\title{
Assessing the feasibility of primary health care provider prescription of anti-hypertensive medication to pregnant women in Bangladesh
}

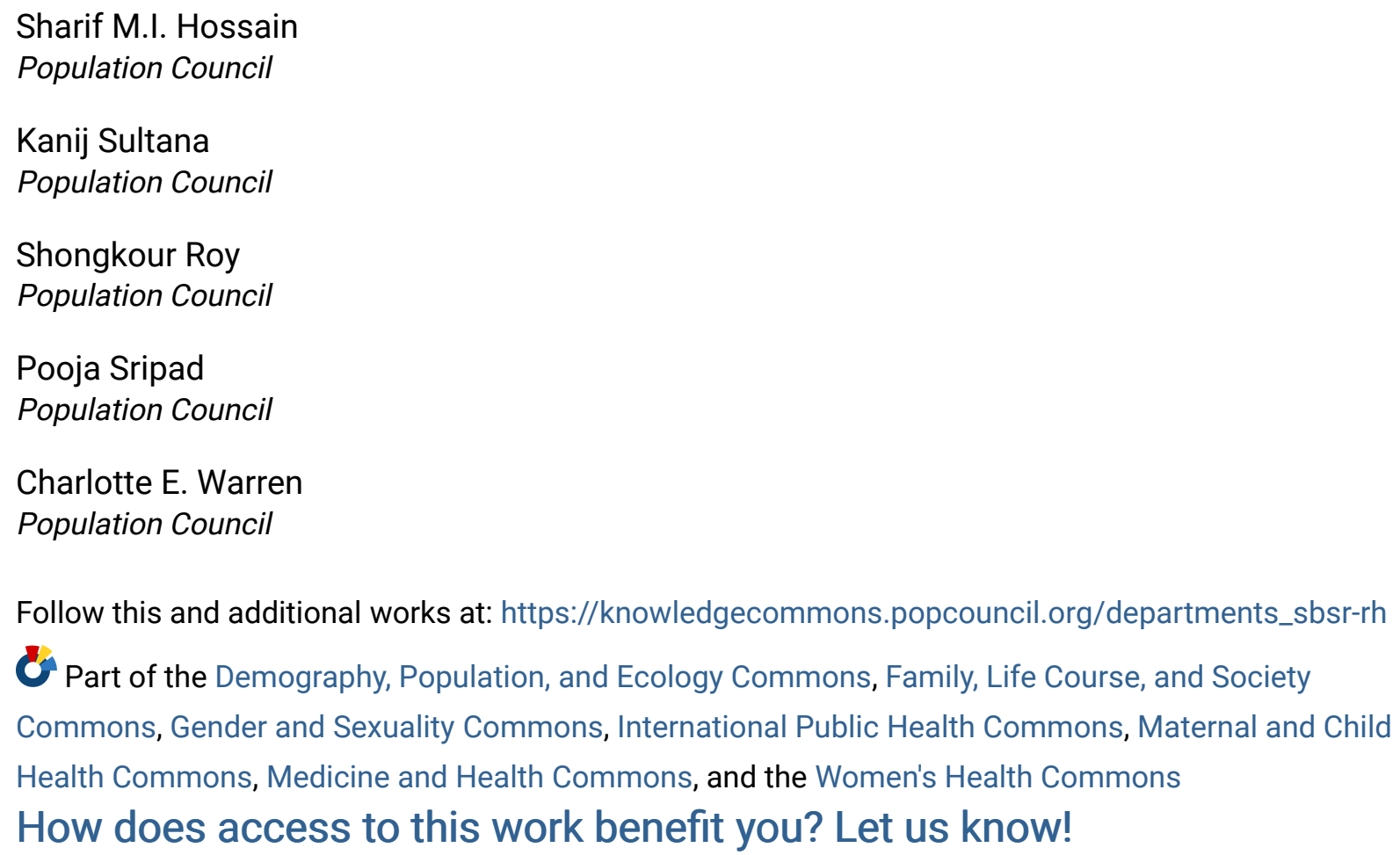

\section{Recommended Citation}

Hossain, Sharif M.I., Kanij Sultana, Shongkour Roy, Pooja Sripad, and Charlotte E. Warren. 2019.

"Assessing the feasibility of primary health care provider prescription of anti-hypertensive medication to pregnant women in Bangladesh," Ending Eclampsia Anti-hypertensive Study Report. Washington, DC:

Population Council. 


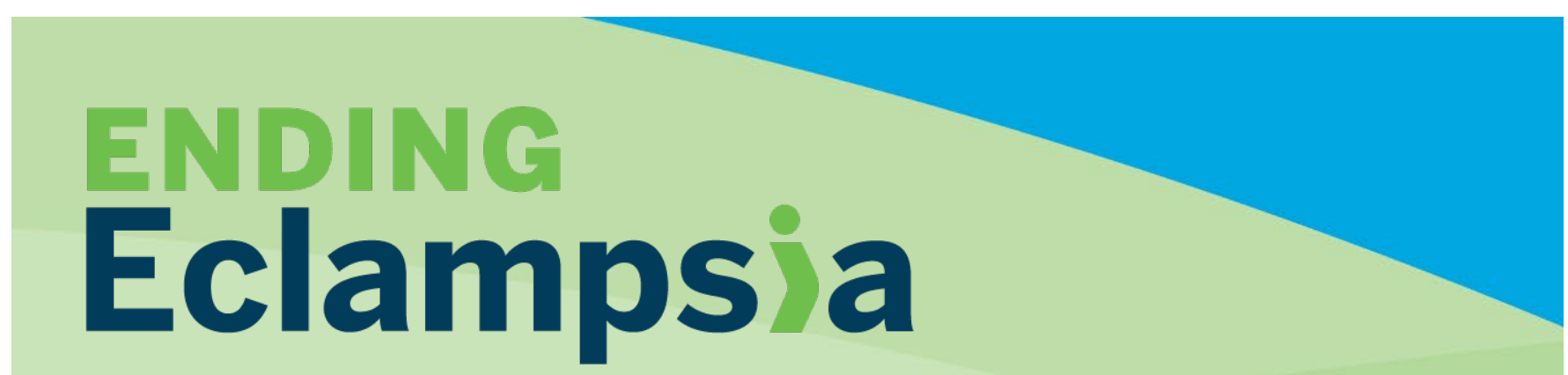

\section{Assessing the Feasibility of Primary Health Care Provider Prescription of Anti-Hypertensive Medication to Pregnant Women in Bangladesh}

Sharif Hossain Kanij Sultana Shongkour Roy Pooja Sripad Charlotte Warren

August 2019 


\section{ENDING}

Ending Eclampsia seeks to expand access to proven, under-utilized interventions and commodities for the prevention, early detection, and treatment of pre-eclampsia and eclampsia and strengthen global partnerships. This research report is part of series of implementation research activities conducted by the Ending Eclampsia project in Bangladesh and focuses on assessing the feasibility and acceptability of PHC providers to identify and treat pregnancy associated hypertension using single dose alpha methyldopa and refer.

\section{POPULATION COUNCIL \\ Ideas. Evidence. Impact.}

The Population Council confronts critical health and development issues-from stopping the spread of HIV to improving reproductive health and ensuring that young people lead full and productive lives. Through biomedical, social science, and public health research in 50 countries, we work with our partners to deliver solutions that lead to more effective policies, programs, and technologies that improve lives around the world. Established in 1952 and headquartered in New York, the Council is a non-governmental, non-profit organization governed by an international board of trustees.

Population Council

4301 Connecticut Avenue NW, Suite 280

Washington DC, 20008

Tel: +1. 877.237.9400

www.popcouncil.org

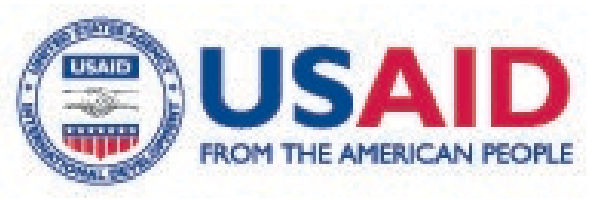

The Ending Eclampsia project is made possible by the generous support of the American people through the United States Agency for International Development (USAID) under the terms of USAID APS-OAA-A-14-00048. The contents of this report are the sole responsibility of the Ending Eclampsia project and the Population Council and do not necessarily reflect the views of USAID or the United States Government.

(c) 2019 The Population Council, Inc. 


\section{Assessing the Feasibility of Primary Health Care Provider Prescription of Anti-Hypertensive Medication to Pregnant Women in Bangladesh}

Sharif Hossain

Kanij Sultana Shongkour Roy Pooja Sripad Charlotte Warren 


\section{Contents}

List of Acronyms

Acknowledgments ..............................................................................................................................

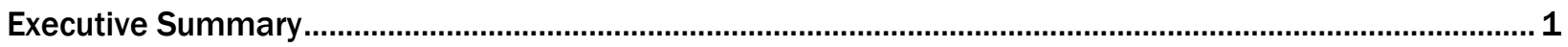

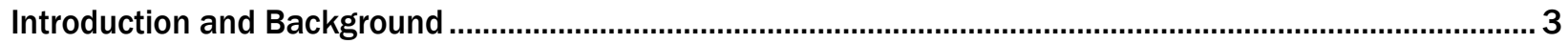

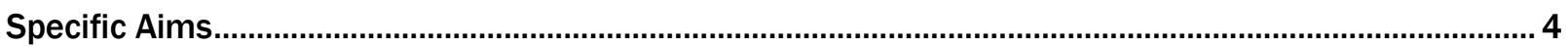

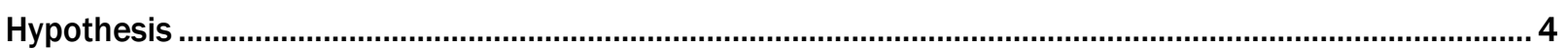

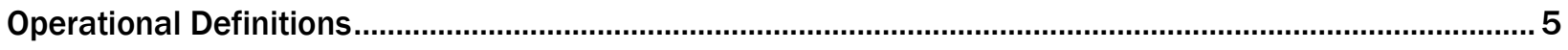

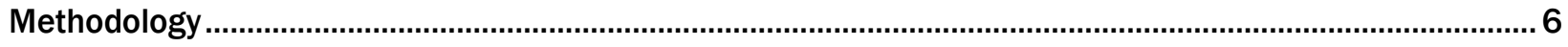

Study Setting

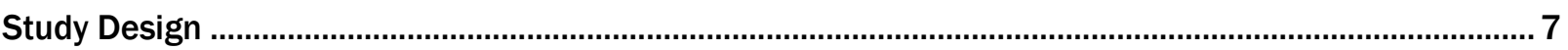

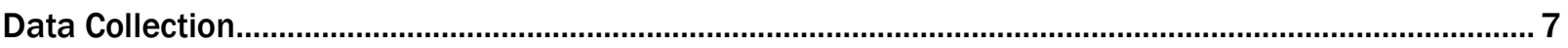

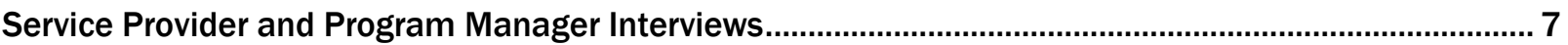

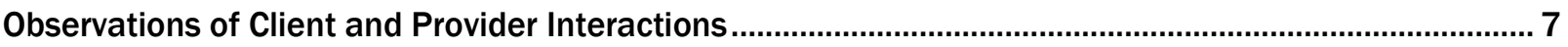

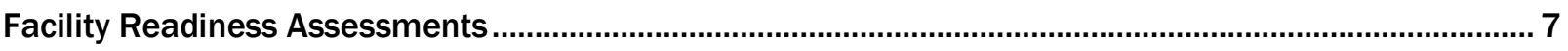

Collection of Service Statistics ......................................................................................................... 7

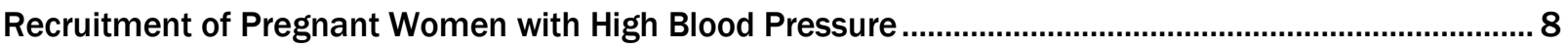

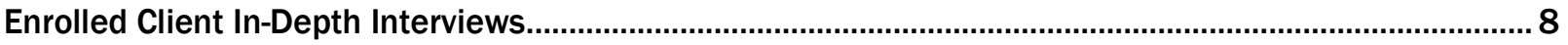

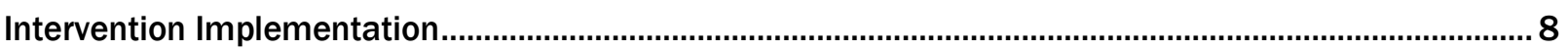

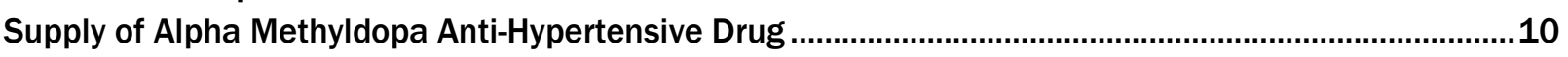

Client Referrals

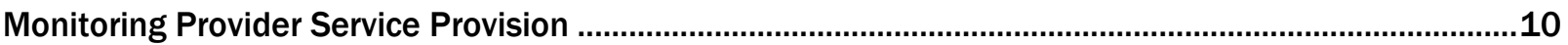

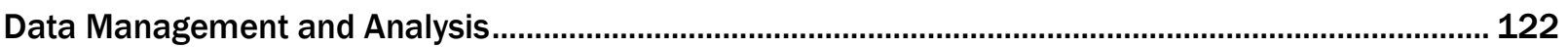

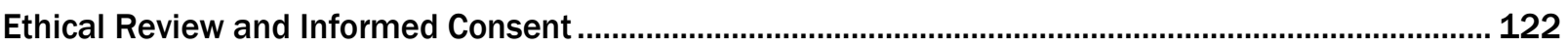

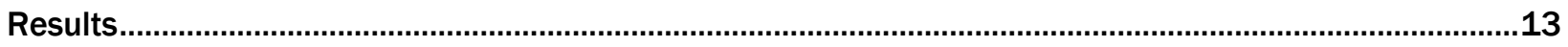

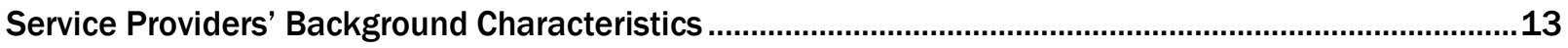

Pregnant with Hypertensive Disorders' Background Characteristics........................................................13

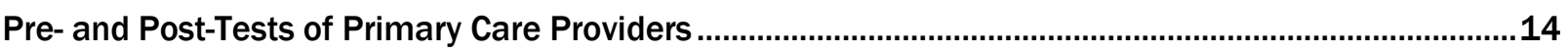

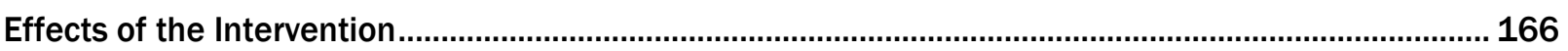

Perception and Practice of Anti-Hypertensive Drug Use ................................................................

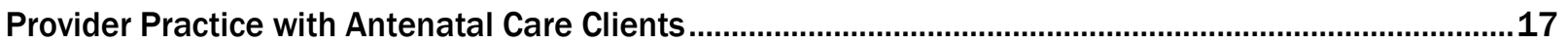

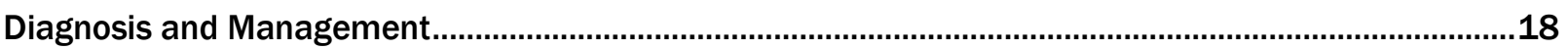

Pregnancy Outcomes for Women with Hypertensive Disorders ............................................................19

Facility Readiness for Services to Hypertensive Clients......................................................................20

Antenatal Care Utilization and Hypertension in Pregnancy Detection...................................................20

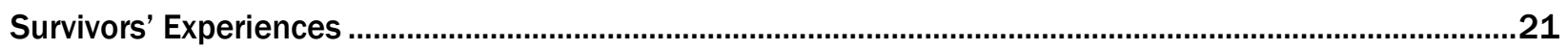

Views of Policy-Makers, Program Managers and Other Stakeholders...................................................23

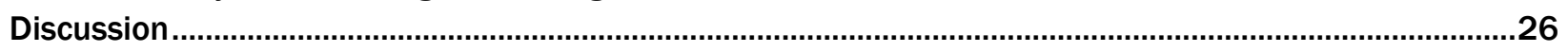

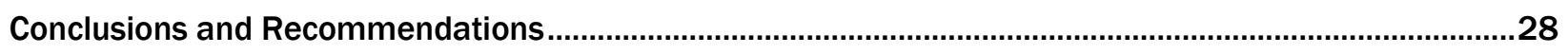

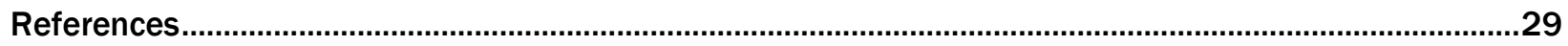

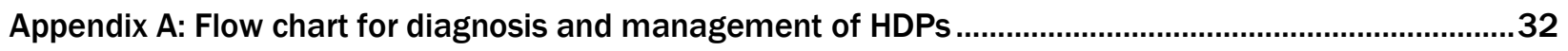

Appendix B: Decision making tree for diagnosis, management, action and referral for PE/ ....................33

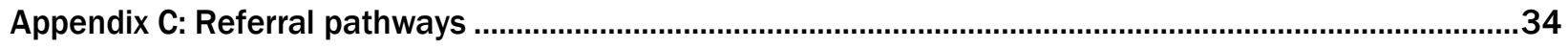

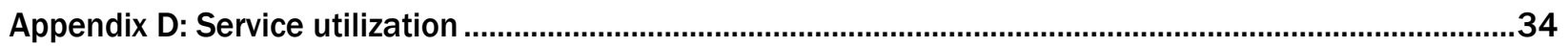




\section{List of Acronyms}

\begin{tabular}{|c|c|}
\hline $\mathrm{AE}$ & Adverse Event \\
\hline ANC & Antenatal Care \\
\hline BMMS & Bangladesh Maternal Mortality Survey \\
\hline BMRC & Bangladesh Medical Research Council \\
\hline CS & Civil Surgeon \\
\hline CVA & Cerebrovascular Accident \\
\hline dBP & Diastolic Blood Pressure \\
\hline DDFP & Deputy Director Family Planning \\
\hline DGFP & Directorate General of Family Planning \\
\hline DGHS & Directorate General of Health Services \\
\hline $\mathrm{DH}$ & District Hospital \\
\hline FWV & Family Welfare Visitor \\
\hline H\&FWC & Health and Family Welfare Centre \\
\hline MCH-FP & Maternal Child Health-Family Planning \\
\hline MCWC & Mother and Child Welfare Centre \\
\hline $\mathrm{MgSO}_{4}$ & Magnesium Sulphate \\
\hline $\mathrm{MH} / \mathrm{RH}$ & Maternal Health/Reproductive Health \\
\hline MoHFW & Ministry of Health and Family Welfare \\
\hline $\mathrm{N} / \mathrm{MW}$ & Nurses/Midwives \\
\hline NICE & National Institute for Clinical Excellence \\
\hline NIE & Net Intervention Effect \\
\hline NTC & National Technical Committee \\
\hline Ob/Gyn & Obstetrics and Gynecology \\
\hline OGSB & Obstetrical and Gynecological Society of Bangladesh \\
\hline PE & Pre-Eclampsia \\
\hline $\mathrm{PE} / \mathrm{E}$ & Pre-Eclampsia/Eclampsia \\
\hline PHC & Primary Health Care \\
\hline PNC & Postnatal Care \\
\hline RA & Research Assistant \\
\hline $\mathrm{RCT}$ & Randomized Control Trial \\
\hline RH & Reproductive Health \\
\hline SACMO & Sub-Assistant Community Medical Officer \\
\hline SAE & Serious Adverse Event \\
\hline sBP & Systolic Blood Pressure \\
\hline UHC & Upazila Health Complex \\
\hline UHFWC & Union Health and Family Welfare Centre \\
\hline USAID & United States Agency for International Development \\
\hline WHO & World Health Organization \\
\hline
\end{tabular}




\section{Acknowledgments}

This report is based on implementation research findings on assessing the feasibility of primary health care providers to prescribe anti-hypertensives to hypertensive pregnant women in Bangladesh. Intervention scale up and implementation science studies were conducted in collaboration with Directorate General of Family Planning (DGFP) and extended support from Directorate General of Health Services (DGHS) and Obstetric \& Gynecological Society of Bangladesh (OGSB). We like to express our sincere gratitude to Dr. Kazi Mustafa Sarwar, Director General, DGFP, MoH\&FW for his keen interest on the subject and extending his wholehearted support to run the program.

We appreciate the United States Agency for International Development (USAID) for their technical and financial support, and for providing necessary guidance to expand utilization of magnesium sulfate $\left(\mathrm{MgSO}_{4}\right)$ and implementation science studies. Particular thanks to Ms. Emily Hillman, Dr. Samina Choudhury, and Ms. Edna Jonas who have given their continuous guidance to complete the studies. We would also like to acknowledge MacArthur Foundation's support for part of the study, commodities, and equipment.

We would like to express our sincere thanks and gratitude to Dr. Mohammed Sharif, Director (MCHServices) and Line Director MCRAH, DGFP for his leadership and guidance for expanding utilization of $\mathrm{MgSO}_{4}$ and completion of implementation science studies. We would also like to thank Dr. Tapash Ranjan Das, former Deputy Director, MCH, MCH Unit, DGFP; Dr. Fahmida Sultana, Deputy Director, MCH services; Dr. Farid Uddin Ahmed, Deputy Director, MCH (RAH), DGFP; Dr. ABM Shamsuddin Ahmed, PM (Support Service \& Co-ordination), MCH Unit, DGFP; and Dr. Nasima Khatun, Deputy Program Manager (MNCAH), DGHS; for their policy and administrative support as well as their cooperation for expanding utilization of $\mathrm{MgSO}_{4}$, completion of implementation science studies, assistance in data collection, and monitoring of program implementation.

The authors would like to express their sincere thanks to Civil Surgeons and Deputy Directors of Family Planning, UH\&FPOs, UFPOs and Ob/Gyn consultants of Cumilla and Tangail districts for their tremendous support during expanding utilization of $\mathrm{MgSO}_{4}$, training, implementing implementation science studies, data collection and monitoring. We would like to acknowledge the participating service providers who successfully completed the project activities. We appreciate their dedication and acknowledge their performance.

Regards and thanks are due to all respondents who made their valuable time available to provide interviews. We are indebted and respectful to those mothers who gave their time and patience by providing interviews and valuable information. Without their cooperation, the study would not have been possible.

Finally, we appreciate our colleagues at the Population Council who gave their efforts in training, data collection and administrative supports. 


\section{Executive Summary}

Hypertensive disorders of pregnancy (HDPs)-which are major contributors of maternal and newborn mortality, morbidity, and disability-are preventable. About 24 percent of maternal deaths in Bangladesh each year are due to pre-eclampsia and eclampsia (PE/E). A known cause of death in women with $\mathrm{PE} / \mathrm{E}$ is cerebrovascular accident (CVA), which occurs due to rapidly increasing blood pressure (BP). Elevated BP associated with pregnancy should be detected and appropriately managed before onset of convulsions (eclampsia) and other life-threatening complications. For women presenting with severe PE/E, magnesium sulphate $\left(\mathrm{MgSO}_{4}\right)$ is the recommended drug for convulsion management. Anti-hypertensive medicines are also recommended for control of high BP, but the authorization to prescribe anti-hypertensive drugs, both for preventing and managing $\mathrm{PE} / \mathrm{E}$, is limited within lower level primary health care (PHC) facilities in Bangladesh. This study assessed the feasibility of PHC providers' identification of HDP and prescription of alpha methyldopa (500mg single dose), prior to their referrals of patients to a higher level facility for $\mathrm{MgSO}_{4}$ administration, if needed.

This 15 month quasi-experimental study was part of the larger Ending Eclampsia project, to scale up a PHC model for early detection, prevention, and management of PE/E using a loading dose of $\mathrm{MgSO}_{4}$. The prepost study design featured both qualitative and quantitative data collection methods at baseline (2017) and endline (2018), in four sub-districts of Cumilla and Tangail districts, with two sub-districts (31 facilities) included in the intervention and the other two serving as comparison sub-districts (23 facilities).

The intervention trained service providers on HDP and classification of hypertension, use and prescription of anti-hypertensive drugs (alpha methyldopa), and immediate referrals for patients to higher level facilities. Comparison facilities received training on HDP and referrals only-but did not receive training on prescription and use of anti-hypertensive drugs. Providers in the intervention facilities received a two day competency-based training followed up with a one day refresher training, while providers in comparison facilities received one day of training only. The World Health Organization (WHO) protocol for hypertension and anti-hypertensive drugs were used in the training.

Almost all PHC providers from both groups, the intervention and comparison, at baseline and endline knew the correct definition of hypertension ( $\geq 140 / 90 \mathrm{mmHg}$ during pregnancy), and the correct drugs for BP control during pregnancy. Similarly, at endline almost all PHC providers knew types of hypertension during pregnancy, and classified mild, moderate, and severe hypertension correctly. Facility data show that a high proportion of women in both comparison and intervention facilities had their BP measured during the three month baseline period and the 15 month intervention period. There was significant improvement in knowledge of when to initiate anti-hypertensive drugs at endline among PHC providers in the intervention group (65\%), compared to the comparison group (20\%) ( $p<0.001)$. PHC provider knowledge of specific drug use (alpha methyldopa) to control BP during pregnancy also significantly improved at endline in the intervention group. Although not significant, about one third of providers in the intervention group prescribed alpha methyldopa at endline, compared to one sixth in the comparison group.

Significant positive changes from baseline to endline were also observed for history-taking for hypertension or high BP $(p<0.05)$ and albumin in urine tests $(p<0.001)$ among intervention providers. In intervention facilities, 10 percent more women had their urine tested for albumin during the intervention period than during the baseline period.

All women with moderate to severe hypertension at intervention facilities who required anti-hypertensives received alpha methyldopa-compared to no such women receiving it in the comparison group $(p<0.001)$. Moreover, 45 percent of women with severe $\mathrm{PE}$ in the intervention group received a loading dose of $\mathrm{MgSO}_{4}$ upon diagnosis, compared to 38 percent of women in the comparison group $(p<0.001)$. 
Almost all women (97\%) with moderate to severe hypertension in all facilities were referred to higher level facilities for further management, with 62 percent of women from intervention facilities, and 51 percent from comparison facilities, actually completing the referral process at another facility.

Study researchers followed all women from both groups, throughout their pregnancies, to assess their pregnancy outcomes. There were no significant differences between the two groups in gestational age at delivery, mode or place of delivery, assistance during delivery, or maternal outcomes. No maternal deaths occurred in either group over the 15 month intervention period, among those who sought services from these facilities.

There were significant differences in newborn outcomes-live, stillborn, or ill-between the two groups $(p=0.001)$. Significantly more infants died in the comparison group $(14 \%, n=9)$ than in the intervention group (3\%, n=3). Among women with HDPs, about four fifths delivered at 36 weeks or later in both groups, while a small proportion in both groups delivered before 33 weeks. Further analysis shows that hypertensive pregnant women who took alpha methyldopa were 1.36 times more likely to deliver a live infant than those who did not (AOR: 1.36, 95\% Cl:0.30-5.43).

PHC providers demonstrated the ability to apply their knowledge correctly in hypertension detection and classification, as well as referring patients when appropriate. Policy-makers, program managers, service providers, and other stakeholders strongly suggest allowing PHC providers to prescribe anti-hypertensive drugs during pregnancy, and recommend scale up of this intervention in other parts of the country to achieve SDGs. The following recommendations emerged from this study:

- PHC providers (FWVs, SACMOs, nurses) are capable of correctly measuring and classifying blood pressure and prescribing a single dose of alpha methyldopa prior to patient referrals to higher level facilities. This practice should be promoted.

- PHC providers can be trained within three days on hypertension, $\mathrm{PE} / \mathrm{E}, \mathrm{MgSO}_{4}$, and antihypertensive drugs, followed by a one day refresher workshop after three months.

- Many women are not completing their referral courses, and further research is recommended to identify why women do not complete the referral process, and to understand these barriers and how to support women's fulfillment of necessary higher level care.

- To build on this study, which looked at a single dose of alpha methyldopa and referral, a pregnancy life course study with anti-hypertensive drugs prescribed by PHC providers is recommended, to assess their abilities to identify drug non-responsiveness, emerging danger signs and symptoms, appropriate times for hospitalization or physician intervention, as well assessing whether task sharing is correctly and adequately implemented.

- The task sharing efforts with anti-hypertensive drugs, particularly alpha methyldopa, demonstrated within Ending Eclampsia's PHC PE/E intervention, are recommended for other parts of the country, to reduce maternal and perinatal morbidities and mortality and to achieve the SDGs by 2030. 


\section{Introduction and Background}

Globally, about 10 percent of women experience a hypertensive disorder in pregnancy (HDP), a major contributor to maternal and newborn mortality, morbidity, and disability (Duley et al 2009, Steegers et al 2010, Khan et al 2006). HDPs are classified into four categories, as recommended by the National High Blood Pressure Education Program Working Group on High Blood Pressure in Pregnancy: 1) chronic hypertension, 2) pre-eclampsia/eclampsia (PE/E), 3) pre-eclampsia (PE) superimposed on chronic hypertension, and 4) gestational hypertension (Mammaro et al 2009).

Pre-eclampsia, which is high blood pressure (BP) with significant proteinuria after 20 weeks of pregnancy gestation, complicates four to five percent of pregnancies (Steegers et al 2010, Abalos et al 2013, Arulkumaran et al 2013). Women in low- and middle income countries (LMICs) are seven times more likely to develop PE than those in higher income countries (WHO 2007). About 10 percent of PE patients develop severe PE/E (WHO 2011). Worldwide, about 14 percent of maternal deaths are due to HDPs (Say et al 2014, WHO 2005, WHO 2007). Timely and effective care can prevent these deaths (Duley et al 2006).

Factors preventing women from seeking or receiving care include poverty, distances to facilities, lack of relevant information, inadequate services, and cultural practices. Poor women in remote areas are least likely to receive adequate health care, especially in regions with low numbers of skilled health providers, such as sub-Saharan Africa and South Asia (PE Foundation 2016).

Some women entering pregnancy may have pre-existing risk factors for HDP development, such as diseases like diabetes, chronic hypertension, chronic kidney disease, or autoimmune disease, or experienced HDP during a previous pregnancy, in addition to obesity, primiparity, age below 20 or older than 35, or a family history of HDP (Meads et al 2008, Action on Preeclampsia 2004). Women who have had gestational hypertension or PE are also associated with increased risk of developing high BP and complications later in life. Women with a history of PE but no proteinuria or hypertension at postnatal review (6 to 8 weeks after birth) have increased relative risk of kidney disease. Women with gestational hypertension have a risk of developing gestational hypertension in a future pregnancy ranging from about 16 percent to 47 percent, and their risk of developing PE in a future pregnancy ranges from two percent to seven percent.

Among women with $\mathrm{PE}$, their risk of gestational hypertension in a future pregnancy ranges from about 13 percent to 53 percent, and their risk of developing PE again is 16 percent. The risk of developing PE in a future pregnancy increases to 25 percent if PE was complicated by severe PE, HELLP syndrome (a lifethreatening pregnancy complication characterized by hemolysis, elevated liver enzymes and low platelet count) or eclampsia, or pre-term birth before 34 weeks, and rises to 55 percent if prior PE led to birth before 28 weeks. Women who have had PE have no additional risk of recurrence with an inter-pregnancy interval up to 10 years (RCOG 2011).

In Bangladesh, HDPs, particularly PE/E, account for 24 percent of pregnant women's deaths (BMMS 2017). A known cause of death in women with PE/E is cerebrovascular accident (CVA), due to rapidly increasing BP. Addressing HDP (especially PE/E) in a timely and effective manner reduces maternal morbidity and mortality. PE should be detected and appropriately managed prior to convulsions (i.e. eclampsia) and other life-threatening complications.

Although many countries have approved $\mathrm{MgSO}_{4}$ for use at all levels of their health care systems, barriers persist. Lower level facilities' access to anti-hypertensive drugs and low dose aspirin, for both PE/E management and prevention, is limited. Anti-hypertensives-including labetalol, alpha methyldopa, nifedipine, and hydralazine-are recommended by WHO for control of high BP but are not routine, except among specialists. In Bangladesh, PHC providers are not authorized to prescribe anti-hypertensive drugs 
and are thereby not empowered to treat women presenting with HDPs. PHC providers in Bangladesh apparently do prescribe anti-hypertensives to pregnant women, even without official sanction, although sometimes with incorrect drugs (Warren et al 2015).

WHO proposes task shifting where the health workforce is insufficient to provide adequate coverage with quality care (WHO 2008, 2012). The global recommendations and guidelines on task shifting propose the adoption or expansion of a task shifting approach as one method of strengthening and expanding the health workforce to rapidly increase access to health services. Reorganization and de-centralization of health services according to a task shifting approach can help to address the current shortages of health workers (ibid). Specific reorganization and decentralization recommended by WHO is rooted in the understanding that lower level cadres such as auxiliary nurses and midwives can administer anti-hypertensives for severe hypertension in pregnancy in the context where there is targeted monitoring and evaluation (WHO 2012). Nothing is known about Family Welfare Visitors' (FWVs) and SACMOs', the main actors in PHC facilities in Bangladesh, capability and suitability to provide anti-hypertensive services at PHC level. FWVs and SACMOs are a lower level service provider cadre similar to auxiliary nurses and midwives, with 18 months and 36 months training, respectively. It is plausible that this group of providers can also be equipped with the appropriate and adequate knowledge, skills, and training for the management of moderate to severe hypertension in pregnancy and then refer these women to higher levels for further management.

It is important to provide appropriate anti-hypertensives to women for moderate to severe hypertension in pregnancy at the first contact point with the health system to reduce negative outcomes due to delays in reaching a physician or facility. In Bangladesh, PHC providers are allowed to provide the loading dose of $\mathrm{MgSO}_{4}$ to initiate management of prior to referral. Therefore, FWVs, SACMOs, and nurses should also be equipped with the appropriate knowledge, and skills, in the management of moderate and severe hypertension using the recommended anti-hypertensives and then refer women to higher levels.

The overall aim of this study was to assess the feasibility of PHC providers (FWVs, SACMOs, nurses), to detect HDPs in women, to prescribe alpha methyldopa (single dose) before referral to another facility and if needed, administer $\mathrm{MgSO}_{4}$.The findings of the study will help policy-makers decide if it feasible and acceptable for PHC providers to prescribe anti-hypertensive drugs during pregnancy.

\section{Specific Aims}

- To assess the feasibility of lower level service providers (FWVs, SACMOs, nurses) to identify and classify high BP among pregnant women during ANC visits;

- To assess the ability of lower level service providers (FWVs, SACMOs, nurses) to prescribe the antihypertensive drug-alpha methyldopa (single dose)- appropriately to pregnant women with moderate to severe hypertension including PE/E before referral (this includes prescribing/administering $\mathrm{MgSO}_{4}$ for severe PE/E prior to referral);

- To refer identified patients to secondary facilities/physicians with anti-hypertensive drugs for further assessment and management.

\section{Hypothesis}

- Lower level service providers will be able to identify hypertensive disorders among pregnant women and choose and provide appropriate anti-hypertensive drugs to manage PE/SPE/E. 


\section{Operational Definitions}

Primary Health Care Provider: Family Welfare Visitors (FWVs), Sub Assistant Community Medical Officers (SACMOs), Nurses, and Midwives who sit at: Union Health and Family Welfare Centre (UHFWC) and Upazila Health Complex (UHC), District Hospital (DH) or Mother and Child Welfare Centre (MCWC)

High blood pressure (BP) during pregnancy: BP of pregnant women of 140/90 mmHg or more for two consecutive measurements, four hours apart, otherwise normal BP

Mild hypertension: BP of pregnant women of 140 to $149 / 90$ to $99 \mathrm{mmHg}$ or more for two consecutive measurements, four hours apart

Moderate hypertension: BP of pregnant women of 150 to $159 / 100$ to $109 \mathrm{mmHg}$ for two consecutive measurements, four hours apart

Severe hypertension: BP of pregnant women of $160 / 110 \mathrm{mmHg}$ or more for two consecutive measurements, four hours apart

Chronic hypertension: BP >140/90 before pregnancy, after 20 weeks, or during pregnancy and not resolving postpartum

Gestational hypertension: BP of pregnant women after 20 weeks of pregnancy, during delivery or 48 hours after delivery is $140 / 90 \mathrm{mmHg}$ or more for two consecutive measurements, four hours apart

Pre-Eclampsia: High BP (140/90 mmHg or higher) and excess protein in the urine (albuminuria, presence of an excess of albumin in the urine) determined by dipstick test after 20 weeks of pregnancy in a woman who previously had normal BP

Severe pre-eclampsia: Severe pre-eclampsia is pre-eclampsia with severe hypertension and/or with symptoms, and/or biochemical and/or hematological impairment (NICE 2010); diastolic BP $\geq 110 \mathrm{mmHg}$ or systolic $\geq 160 \mathrm{mmHg}$ after two measurements, four hours apart with albumin in urine; and/or with severe headache, and/or blurred vision, and/or pain in upper abdomen

HELLP syndrome: Life-threatening pregnancy complication characterized by hemolysis, elevated liver enzymes, and a low platelet count

Eclampsia: High BP (140/90 mmHg or greater), excess protein in urine (albuminuria/proteinuria), and generalized convulsions or seizures during pregnancy, labor or within 42 days of delivery in the absence of epilepsy or another condition predisposing to convulsions (Sibai 2005); eclampsia occurs 38 percent to 55 percent of the time during pregnancy; 13 percent to 36 percent intrapartum; five percent to 39 percent within 48 hours of childbirth; and five to 17 percent more than 48 hours after birth

Stroke: Hemiparesis and/or blindness developed during pregnancy or in the 42 days postpartum lasting greater than 48 hours

Coma: Prolonged unconsciousness for 12 or more hours. 


\section{Methodology}

\section{Study Setting}

Bangladesh has a uniform health and family planning (FP) infrastructure (Figure 1), with each district featuring a District Hospital (DH) that includes a Mother and Child Welfare Center (MCWC), each managed by the Director General for FP (DGFP). Every sub-district has an Upazila Health Complex (UHC) with a FP unit, and every union has a Union Health and Family Welfare Centre (UH\&FWC) for FP along with 12 to 16 Community Clinics (CCs) for health and FP services. Each district has eight to 10 sub-districts, and every sub-district has eight to 10 unions; unions each have three wards, and each ward has three or four CCs. District hospitals and MCWCs are considered secondary facilities, whereas UHCs, UH\&FWCs, and CCs are considered PHC facilities.

Figure 1. Health and FP Infrastructures in Bangladesh

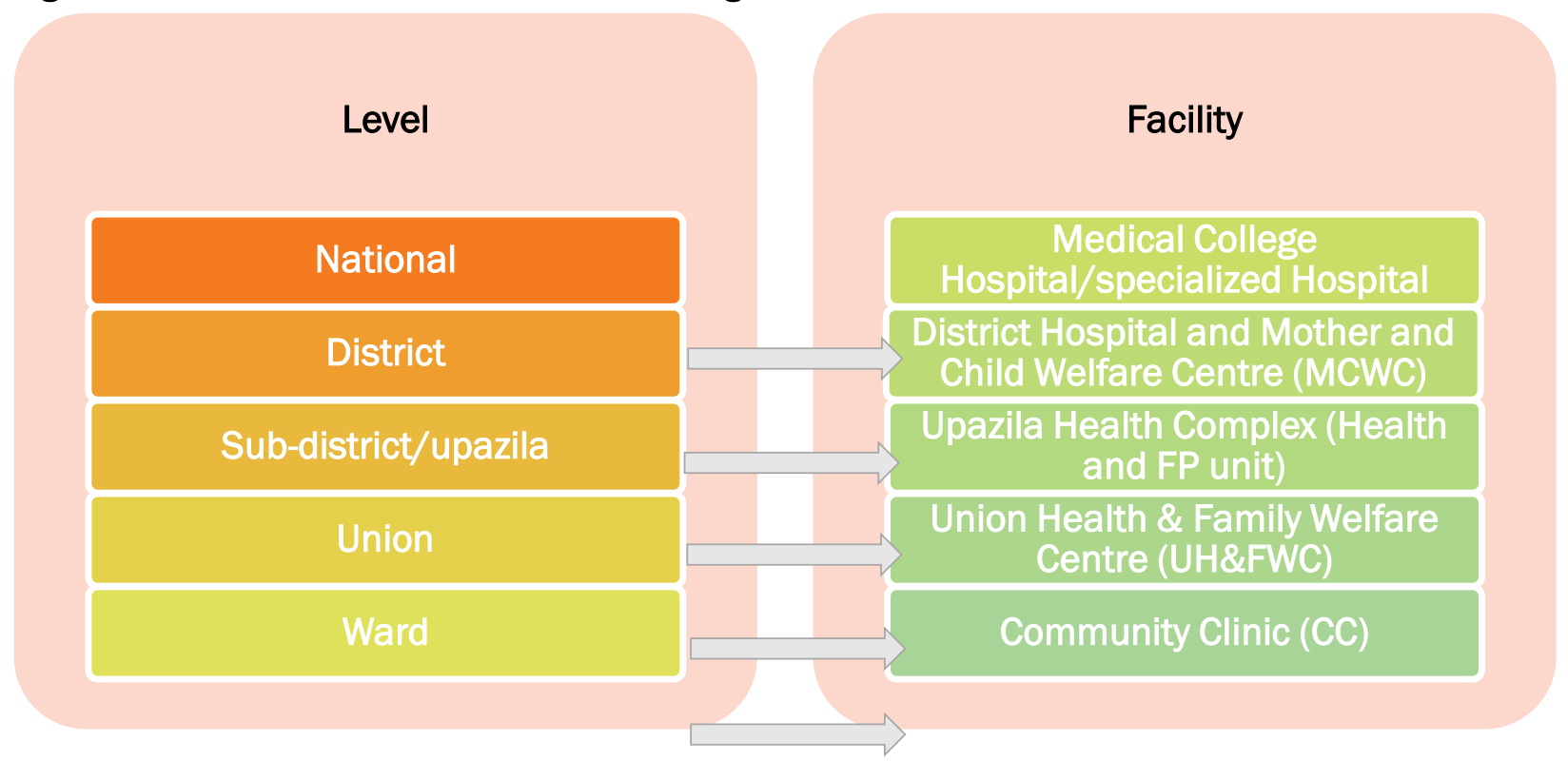

This study was part of a larger study of the Ending Eclampsia Project, a USAID-funded endeavor supporting the prevention, early detection, and management of PE/E at PHC facilities in four districts in Bangladesh. Ending Eclampsia's primary study involved 136 facilities-including 116 UH\&FWCs, 11 UHCs, five MCWCs, two DHs, and two medical colleges-in 12 sub-districts, and trained PHC providers to detect (e.g. measure $\mathrm{BP}$, test urine for albumin) and manage $\mathrm{PE} / \mathrm{E}$ (administer loading dose of $\mathrm{MgSO}_{4}$ ), and ensured availability of commodities and supplies, along with referrals (Warren et al 2016). All PHC providers provide ANC and PNC services, except male SACMOs, who only provide them in the absence of FWVs and nurses.

This focused study, introducing anti-hypertensive drugs at PHC facilities, was conducted in four sub-districts of Cumilla and Tangail districts, following consultations with DGFP. Two sub-districts were assigned to the intervention (29 facilities) and two were assigned to the comparison (21 facilities) including four referral facilities (UHCs) and were similar in health infrastructure, service providers, populations, fertility, and health-seeking behaviors. This study was implemented at UH\&FWCs and UHCs, as well as in both districts' DHs, MCWCs, and medical colleges, as referral facilities. 


\section{Study Design}

The study employed a quasi-experimental design with two sub-districts each assigned intervention and comparison sites. There was enough distance between the sub-districts to avoid any contamination. All PHC facilities in the four sub-districts were included in the study, in addition to district referral facilities.

\section{Data Collection}

Service statistics were collected for three months preceding the study, and then monthly throughout the 15 months of the study.

\section{Service Provider and Program Manager Interviews}

PHC service providers' knowledge, attitudes, and practices (KAP) were assessed in two ways. To assess their knowledge acquired through training by the project, pre- and post-training tests were conducted through self-administered questionnaires. Secondly, the research team administered a cross-sectional survey in all 54 PHC facilities including the four referral facilities, to assess service providers' KAP at prior to the intervention and after the 15 month intervention period. Additional questions were added to the service providers' questionnaire at the 15 month assessment to assess program impact. Ten program managers working in the four sub-districts and eight central policy-makers and other stakeholders were interviewed after 15 months as well for their opinions and experiences of PHC providers' administration of anti-hypertensive drugs. The primary sampling unit was a health care facility, and service provider data were collected from trained, re-trained, and mentored providers after 15 months. It is possible that service providers, program managers, and policy-makers were not at the same facilities as during initial baseline due to transfers or new postings; however, newly posted providers were all trained for the intervention.

\section{Observations of Client and Provider Interactions}

Client and provider interactions (CPIs) were observed both before $(n=99)$ and after $(n=129)$ the intervention in all study sites, using a checklist. CPI observations focused on PHC provider practices with ANC clients, specifically for PE/E including BP measurement, history taking, urine testing, and client documentation. Upon explaining the study's objectives and purposes, the research assistant obtained permission from each PHC provider as well as every client, for their observation of service provision and client documentation.

\section{Facility Readiness Assessments}

Facility readiness of the core PE/E intervention of Ending Eclampsia project was assessed three months before the anti-hypertensive study. Additionally, a post-intervention assessment was conducted after the 15 month intervention period. The facility readiness assessment was conducted to determine the availability of commodities and equipment for effective managements of HDPs. The pre- and postintervention assessments were conducted in all comparison and intervention facilities.

\section{Collection of Service Statistics}

Three months of pre-intervention service statistics on hypertension and PE/E among ANC clients were collected from all study facilities. Subsequently, monthly service statistics for 15 months (May 2017 to July 2018) were also collected on hypertension and PE/E at all facilities and compared with baseline preintervention service statistics, from February to April 2017, to determine if the intervention had any impact on identification of hypertension and PE/E among ANC clients. 


\section{Recruitment of Pregnant Women with High Blood Pressure}

Any ANC client with moderate to severe hypertension from both intervention and comparison facilities who were 15 years of age or older, had chronic or gestational increased BP, with any duration of pregnancy, and agreed to participate in the study and provided informed consent, was enrolled in the study by the service providers using an enrolment form. Although the age of consent in Bangladesh is 18 years, pregnant women younger than 18 are considered emancipated by virtue of their marital and pregnancy status. Upon explaining the study objectives and purposes, eligible clients consented to PHC providers to enroll in the study and providers invited eligible clients to participate to fill-up enrolment form in the study. Addresses, socio-demographic characteristics, and telephone numbers of those who agreed to participate were recorded on the enrolment form by service providers. Participants' permission was also taken to conduct follow up interviews in their homes during postnatal period. Interviewers reminded each respondent they had agreed to a follow up interview by showing them the enrolment form. All respondents gave their consent to take part in this study. Interviewers informed respondents on the purpose of the follow up interview and obtain consent again before starting the interview. Each enrolled client was followed-up until delivery and into the postnatal period to determine compliance with referral and pregnancy outcomes by DMOs.

\section{Enrolled Client In-Depth Interviews}

A sample of enrolled participants from both intervention and comparison facilities participated in in-depth interviews to explore their perceptions on quality of care received at the facility during the study as well as the referral process. The clients were interviewed at their homes.

TABLE 1 Quantitative and qualitative data collection by intervention and comparison facilities

\begin{tabular}{|c|c|c|c|c|c|c|}
\hline \multirow{2}{*}{ Type of data } & \multicolumn{3}{|c|}{ Baseline } & \multicolumn{3}{|c|}{ Endline } \\
\hline & Intervention & Comparison & Total & Intervention & Comparison & Total \\
\hline \multicolumn{7}{|l|}{ Quantitative data collection } \\
\hline Service provider interview & 49 & 52 & 101 & 47 & 50 & 97 \\
\hline Interview with women with HDP & - & - & - & 89 & 63 & 152 \\
\hline Client provider interaction & 57 & 42 & 99 & 70 & 59 & 129 \\
\hline Facility Inventory: commodities/supplies & 31 & 23 & 54 & 31 & 23 & 54 \\
\hline \multicolumn{7}{|l|}{ Qualitative data collection } \\
\hline IDIs with Program Manager (sub-district) & \multicolumn{3}{|c|}{-} & 5 & 5 & 10 \\
\hline IDIs with Policy-makers (central) & & & & - & - & 8 \\
\hline IDIs with HDP women & \multicolumn{3}{|c|}{-} & 13 & 7 & 20 \\
\hline \multirow{2}{*}{$\begin{array}{l}\text { Monitoring service statistics } \\
\text { (18 months) }\end{array}$} & \multicolumn{3}{|c|}{3 months } & \multicolumn{3}{|c|}{15 months } \\
\hline & \multicolumn{6}{|c|}{$\begin{array}{l}\text { Monthly service uptake collected from } 54 \text { facilities for } 18 \\
\text { months including } 3 \text { months pre-intervention data }\end{array}$} \\
\hline
\end{tabular}

IDIs: in-depth interviews

\section{Intervention Implementation}

Service providers in the intervention facilities received training on three components: 1 ) on HDPs and classification of hypertension, 2) on one anti-hypertensive drug (alpha methyldopa), and 3) on when to refer to a higher facility. Providers were also trained in the two comparison sub-districts, but did not receive training on alpha methyldopa, instead they were advised to refer any client with high BP (Table 2). 
TABLE 2 Intervention design

\begin{tabular}{|l|c|c|}
\hline Intervention & $\begin{array}{c}\text { Intervention } \\
\text { group }\end{array}$ & $\begin{array}{c}\text { Comparison } \\
\text { group }\end{array}$ \\
\hline $\begin{array}{l}\text { Training service providers (FWVs, SACMOs, nurses) on HDPs and HTN } \\
\text { classification }\end{array}$ & $\checkmark$ & $\checkmark$ \\
\hline $\begin{array}{l}\text { Training of service providers (FWVs, SACMOs, nurses) on alpha methyldopa } \\
\text { (procured and made available in study facilities by the project) }\end{array}$ & $\checkmark$ & \\
\hline Referral to a higher level facility & $\checkmark$ & - \\
\hline
\end{tabular}

Providers at intervention facilities were provided a two day competency-based training followed by a one day refresher workshop three months after the initial training. Trainings were facilitated by master trainers from the Ending Eclampsia project selected from both local and central MoHFW units, along with experts from the Obstetrics and Gynecological Society of Bangladesh (OGSB) and Population Council staff. Pre- and post-training tests assessed immediate changes in provider knowledge. The training curriculum was based on World Health Organization (WHO) guidelines and Bangladesh's national service delivery protocol for PE/E (WHO 2011, DGFP 2015). Hypertension diagnosis and treatment protocols (Appendix A) and a referral "decision tree" for HDPs (Appendix C), developed from Jhpiego Helping Mother Survives and WHO recommendations, were supplied to providers to guide their detection, management, and referral of women with HDPs.

The hypertension diagnosis and treatment protocol and decision tree describe ways of identifying HDP during ANC and PNC visits, how to classify hypertension as chronic HTN, gestational hypertension or preeclampsia, differences between HTN and PE/E, the definitions of mild, moderate and severe HTN and PE/E, and management of $\mathrm{HTN}$ and $\mathrm{PE} / \mathrm{E}$. The guidelines also provide information on grading hypertension as mild, moderate and severe, and management for each category.

Provider training also included a skills-building session for correctly measuring BP, how to conduct an albumin test of urine with dipsticks, when to administer alpha methyldopa, and patient counseling and referral processes. Providers were also informed of why and how to correctly document essential ANC service elements, alpha methyldopa and $\mathrm{MgSO}_{4}$ provision, and referrals. Providers were also oriented on the study's procedures, ethical issues, as well as participant enrollment processes and informed consent procedures.

PHC providers were trained only to prescribe and dispense a single dose of alpha methyldopa since the National Technical Committee approved only a test of this drug.

- For mild hypertension, providers in intervention facilities were trained to only monitor BP regularly.

- For moderate hypertension, providers in intervention facilities were advised to prescribe a single $500 \mathrm{mg}$ dose of alpha methyldopa and then refer to a facility or physician for further management.

- For severe hypertension, providers in intervention facilities, in addition to prescribing a single 500mg dose of alpha methyldopa, administered a loading dose of $\mathrm{MgSO}_{4}$ and referred patients to referral facility for further management.

Providers in comparison facilities participated in a one day training on identifying hypertensive pregnant women and referring patients to secondary facilities. They were not trained on alpha methyldopa. Job aids on managing hypertension with alpha methyldopa were not provided to comparison facility PHC providers.

The refresher workshop for providers at intervention facilities was organized for one day, three months after their initial training, to review providers' activities, share their experiences with patients, resolve any issues, and further update their knowledge of the anti-hypertensive drug and PE/E. 
In addition to these trainings, PHC providers at intervention facilities were mentored on detecting, classifying, and managing HDPs including hypertension (systolic BP [sBP] of $\geq 140 \mathrm{mmHg}$ and or diastolic $\mathrm{BP}$ [dBP] of $\geq 90 \mathrm{mmHg}$ measured on two different occasions, two hours apart), chronic hypertension (isolated hypertension diagnosed before the index pregnancy or detected before 20 weeks of gestation and continue after delivery), gestational hypertension (isolated hypertension diagnosed for the first time after 20 weeks of index pregnancy without proteinuria), and PE (gestational hypertension and proteinuria of $\geq++$ using a urine dipstick).

\section{Supply of Alpha Methyldopa Anti-Hypertensive Drug}

Primary health care providers are not allowed to prescribe anti-hypertensive drugs, which are not supplied to PHC facilities by MoHFW. The Ending Eclampsia project, with MacArthur Foundation support, procured alpha methyldopa and distributed it to the study intervention facilities, with each PHC provider supplied a box of 30 alpha methyldopa 500mg tablets. Monitoring visits regularly checked drug supplies for replenishment.

An initial 500mg alpha methyldopa tablet was given to every moderate to severe hypertensive pregnant woman, who were then referred to a physician or referral facility.

\section{Client Referrals}

Women were referred to a physician at a secondary or higher level facility, guided by a decision tree (job aid and treatment algorithm in Appendix A, figures 1 and 2). The BP of women suffering from mild hypertension was monitored in all facilities. If a woman at an intervention facility experienced moderate hypertension, she was given a single dose of alpha methyldopa (500mg) and then referred to a physician or referral facility for further management. In a comparison facility, if a woman suffered from moderate hypertension she was referred to a physician or referral facility for further management without any provision of alpha methyldopa.

Women who experienced severe $\mathrm{PE} / \mathrm{E}$ at both intervention and comparison facilities were administered a $10 \mathrm{mg}$ loading dose of $\mathrm{MgSO}_{4}$ and referred to higher level facilities for further management, and women at intervention facilities were also given a single dose of alpha methyldopa. To track referrals at both intervention and comparison sites, each provider completed a referral slip, providing a duplicate to the client to present at the referral facility. If any referred client did not present at a referral facility, the service provider or District Monitoring Officer (DMO) called the client or her family to directly confirm whether she went to a tertiary facility, and if not, why.

\section{Monitoring Primary Health Care Provider Service Provision}

Service providers and their provision of services were monitored in two ways. PHC providers were monitored and mentored by a project-recruited DMO each month, when client records were reviewed and service statistics were collected to ensure PHC providers' compliance with ethical and clinical standards. DMOs also attended PHC providers' monthly sub-district meetings and cited any issues that needed to be discussed. DMOs also accompanied local supervisors when needed. In addition, a medical professional from the Council conducted quarterly monitoring and mentoring visits, sometimes with central program managers from DGFP and DGHS, to ensure PHC providers' compliance with ethical and clinical standards.

Monitoring visits observed PHC providers' measurement and detection of BP, urine albumin, as well as adverse events, for documentation. When no incidences of hypertension had occurred at a facility, PHC providers were instead asked to detail the treatment protocol and algorithm (Figure 2, next page). 
Figure 2 Diagnosis of type and level of high BP during pregnancy and its management (algorithm for comparison and intervention facilities)

\begin{tabular}{|c|c|c|c|c|c|}
\hline Blood pressure & $\begin{array}{l}\text { Albumin } \\
\text { in urine }\end{array}$ & $\begin{array}{c}\text { Sign/ } \\
\text { Symptom* }\end{array}$ & HTN Diagnosis & $\begin{array}{c}\text { Management } \\
\text { in comparison facilities }\end{array}$ & $\begin{array}{c}\text { Management } \\
\text { in intervention facilities }\end{array}$ \\
\hline \multirow{3}{*}{$\begin{array}{l}\text { Systolic: } \\
\text { 140-149 } \\
\text { mmHg } \\
\text { Diastolic: } \\
90-99 \\
\mathrm{mmHg}\end{array}$} & \multirow[b]{2}{*}{ Yes } & No & $\begin{array}{l}\text { - Mild HTN } \\
\text { - PE }\end{array}$ & - Refer & - Refer \\
\hline & & Yes & $\begin{array}{l}\text { - Mild HTN } \\
\text { - Severe PE }\end{array}$ & $\begin{array}{l}\text { - Injection } \mathrm{MgSO}_{4} \\
\text { loading dose }(10 \mathrm{gm}) \text { ** } \\
\text { - Refer }\end{array}$ & $\begin{array}{l}\text { - Injection } \mathrm{MgSO}_{4} \\
\text { loading dose } \\
(10 \mathrm{gm})^{\star \star} \\
\text { - Refer } \\
\end{array}$ \\
\hline & No & No & Mild HTN & $\begin{array}{l}\text { - Advice to rest } \\
\text { - Return for follow up } \\
\text { after } 3 \text { days } \\
\text { - Refer }\end{array}$ & $\begin{array}{l}\text { - Advice to rest } \\
\text { - Return for follow up } \\
\text { after } 3 \text { days } \\
\text { - Refer }\end{array}$ \\
\hline \multirow{3}{*}{$\begin{array}{l}\text { Systolic: } \\
\text { 150-159 } \\
\mathrm{mmHg}\end{array}$} & \multirow[b]{2}{*}{ Yes } & No & $\begin{array}{l}\text { - Moderate HTN } \\
\text { - } \mathrm{PE}\end{array}$ & - Refer & $\begin{array}{l}\text { - } 1 \text { tablet Alpha } \\
\text { methyldopa (500mg) } \\
\text { - Refer }\end{array}$ \\
\hline & & Yes & $\begin{array}{l}\text { - Moderate HTN } \\
\text { - Severe PE }\end{array}$ & $\begin{array}{l}\text { - Injection } \mathrm{MgSO}_{4} \\
\text { loading dose }(10 \mathrm{gm}) \\
\text { - Refer }\end{array}$ & $\begin{array}{l}\text { - } 1 \text { tablet Alpha } \\
\text { methyldopa }(500 \mathrm{mg}) \\
\text { - Injection } \mathrm{MgSO}_{4} \\
\text { loading dose }(10 \mathrm{gm}) \\
\text { - Refer }\end{array}$ \\
\hline & No & No & - Moderate HTN & - Refer & $\begin{array}{l}\text { - } 1 \text { tablet Alpha } \\
\text { methyldopa (500mg) } \\
\text { - Refer }\end{array}$ \\
\hline \multirow{3}{*}{$\begin{array}{l}\text { Systolic: } \\
160 \mathrm{mmHg} \\
\text { or more }\end{array}$} & \multirow{2}{*}{ Yes } & No & $\begin{array}{l}\text { - Severe HTN } \\
\text { - Severe PE }\end{array}$ & $\begin{array}{l}\text { - Injection } \mathrm{MgSO}_{4} \\
\text { loading dose }(10 \mathrm{gm}) \\
\text { - Refer }\end{array}$ & $\begin{array}{l}\text { - } 1 \text { tablet Alpha } \\
\text { methyldopa }(500 \mathrm{mg}) \\
\text { - Injection } \mathrm{MgSO}_{4} \\
\text { loading dose }(10 \mathrm{gm}) \\
\text { - Refer }\end{array}$ \\
\hline & & Yes & $\begin{array}{l}\text { - Severe HTN } \\
\text { - Severe PE }\end{array}$ & $\begin{array}{l}\text { - Injection } \mathrm{MgSO}_{4} \\
\text { loading dose }(10 \mathrm{gm}) \\
\text { - Refer }\end{array}$ & $\begin{array}{l}\text { - } 1 \text { tablet Alpha } \\
\text { methyldopa (500mg) } \\
\text { - Injection } \mathrm{MgSO}_{4} \\
\text { loading dose }(10 \mathrm{gm}) \\
\text { - Refer }\end{array}$ \\
\hline & No & No & $\begin{array}{l}\text { - Severe HTN } \\
\text { - Severe PE }\end{array}$ & $\begin{array}{l}\text { - Injection } \mathrm{MgSO}_{4} \\
\text { loading dose }(10 \mathrm{gm}) \\
\text { - Refer }\end{array}$ & $\begin{array}{l}\text { - } 1 \text { tablet Alpha } \\
\text { methyldopa }(500 \mathrm{mg}) \\
\text { - Injection } \mathrm{MgSO}_{4} \\
\text { loading dose }(10 \mathrm{gm}) \\
\text { - Refer }\end{array}$ \\
\hline \multirow{2}{*}{$\begin{array}{l}\text { Any high BP } \\
\text { level }\end{array}$} & Yes & Convulsion & Eclampsia & $\begin{array}{l}\text { - Injection } \mathrm{MgSO}_{4} \\
\text { loading dose }(10 \mathrm{gm}) \\
\text { - Refer }\end{array}$ & $\begin{array}{l}\text { - } 1 \text { tablet Alpha } \\
\text { methyldopa }(500 \mathrm{mg}) \\
\text { - Injection } \mathrm{MgSO}_{4} \\
\text { loading dose }(10 \mathrm{gm}) \\
\text { - Refer }\end{array}$ \\
\hline & No & Convulsion & Eclampsia & $\begin{array}{l}\text { - Injection } \mathrm{MgSO}_{4} \\
\text { loading dose }(10 \mathrm{gm}) \\
\text { - Refer }\end{array}$ & $\begin{array}{l}\text { - } 1 \text { tablet Alpha } \\
\text { methyldopa }(500 \mathrm{mg}) \\
\text { - Injection } \mathrm{MgSO}_{4} \\
\text { loading dose (10gm) } \\
\text { - Refer }\end{array}$ \\
\hline
\end{tabular}

*sign/symptom: severe headache, blurred vision and upper abdominal pain; ** while Pritchard regime recommended $14 \mathrm{gm} \mathrm{MgSO}_{4}$ intramuscular, in Bangladesh loading dose of $\mathrm{MgSO}_{4}(10 \mathrm{gm})$ intramuscular was recommended and approved 


\section{Data Management and Analysis}

A 10 member data collection team including two supervisors was recruited and trained for five days on the study's objectives, survey tools, procedures, and ethical conduct of data collection. The researchers were also given practical training in the field on data collection for one day, out of range of the study area. One group of four data collectors and a supervisor was assembled for quantitative data collection, with another group of four interviewers and a supervisor for qualitative data collection.

All completed questionnaires were checked by the supervisors in the field and sent to the Council office for further editing, entry, and analysis. Quantitative data were edited, coded, and analyzed using STATA/SAS software. Data entry employed CSPro, and double entries were performed to minimize data entry errors. Atlas.ti was used for qualitative data analysis.

Descriptive, bivariate, and comparative analyses (Chi-Square test and Fisher's Exact test) were performed, and their results are presented in this report as frequencies and percentages. To answer the research question "Are lower level service providers able to identify, classify and manage hypertensive disorders in pregnancy appropriately with alpha methyldopa?" analysis determined associations and causal effects of the intervention. A difference in difference analysis was conducted, with change effects and mean difference, and net intervention effects (NIE), calculated at 95 percent level of significance.

Qualitative interviews were recorded in hand-written notes reinforced by audio recordings that were transcribed and translated into English. Thematic coding was prepared, and content and thematic analysis employed Atlas.ti. Findings were triangulated in thematic areas.

\section{Ethical Review and Informed Consent}

Ethical review and approval of this study protocol was obtained from both Population Council's Institutional Review Board in New York (as Protocol 731) and the Bangladesh Medical Research Council's (BMRC) Ethics Committee. Participation in this study was voluntary, and all participants were guided through the informed consent process. Only consenting participants were included in the study. 


\section{Results}

\section{Service Providers' Background Characteristics}

There were no significant differences in intervention and comparison facility providers' background characteristics at baseline and endline (Table 3). About four fifths of PHC providers were female at endline at all facilities. Almost all PHC providers had received training on maternal health, FP, and child health within the preceding three years, at baseline and endline, in both intervention and comparison facilities.

TABLE 3 Demographic characteristics of PHC providers in comparison and intervention facilities

\begin{tabular}{|c|c|c|c|c|c|c|}
\hline \multirow[b]{2}{*}{ Characteristic } & \multicolumn{3}{|c|}{ Comparison, n (\%) } & \multicolumn{3}{|c|}{ Intervention, n (\%) } \\
\hline & Baseline & Endline & $\begin{array}{c}\text { p- } \\
\text { value }\end{array}$ & Baseline & Endline & $\begin{array}{c}\text { p- } \\
\text { value }^{a}\end{array}$ \\
\hline \multicolumn{7}{|l|}{ Sex } \\
\hline Female & $34(65.4)$ & $37(74.0)$ & \multirow{2}{*}{0.34} & $38(77.6)$ & $37(78.7)$ & \multirow{2}{*}{0.90} \\
\hline Male & $18(34.6)$ & $13(26.0)$ & & $11(22.4)$ & $10(21.3)$ & \\
\hline \multicolumn{7}{|l|}{ Age (years) } \\
\hline$<30$ & $5(9.6)$ & $6(12.0)$ & \multirow{4}{*}{0.62} & $6(12.2)$ & $5(10.6)$ & \multirow{4}{*}{0.74} \\
\hline $30-39$ & $9(17.3)$ & $9(18.0)$ & & $8(16.3)$ & $12(25.6)$ & \\
\hline $40-49$ & $15(28.9)$ & $19(38.0)$ & & $13(26.5)$ & $11(23.4)$ & \\
\hline$>=50$ & $23(44.2)$ & $16(32.0)$ & & $22(44.9)$ & $19(40.4)$ & \\
\hline \multicolumn{7}{|l|}{ Type of service providers } \\
\hline Nurse/FWV & $30(57.7)$ & $33(66.0)$ & \multirow{2}{*}{0.39} & $31(63.3)$ & $32(68.1)$ & \multirow{2}{*}{0.62} \\
\hline SACMO & $22(42.3)$ & $17(34.0)$ & & $18(36.7)$ & $15(31.9)$ & \\
\hline \multicolumn{7}{|l|}{ Years of work in PHC facility } \\
\hline$<6$ & $22(42.2)$ & $19(38.0)$ & \multirow{3}{*}{0.90} & $18(36.7)$ & $19(40.4)$ & \multirow{3}{*}{0.32} \\
\hline $6-10$ & $15(28.9)$ & $15(30.0)$ & & $17(34.7)$ & $10(21.3)$ & \\
\hline$>10$ & $15(28.9)$ & $16(32.0)$ & & $14(28.6)$ & $18(38.3)$ & \\
\hline Resident at facility & $21(40.4)$ & $19(38.0)$ & 0.81 & $21(42.9)$ & $16(34.0)$ & 0.38 \\
\hline $\begin{array}{l}\text { Received any training } \\
\text { on maternal health, FP, } \\
\text { child health in last } 3 \text { years }\end{array}$ & 49 (94.3) & $50(100.0)$ & $0.24^{b}$ & $47(95.9)$ & $47(100.0)$ & $0.50^{b}$ \\
\hline (n) & (52) & (50) & & (49) & (47) & \\
\hline
\end{tabular}

a Pearson chi-square test, unless otherwise indicated; ${ }^{b}$ Fisher's exact test

\section{Pregnant Women with Hypertensive Disorders' Background Characteristics}

While educational status and gestational age were similar in both groups of pregnant women, there were significantly more multipara women recruited in the intervention group than in the comparison group $(p<0.05)$. There was no substantial difference in proteinuria detected in women in either facility group, however there was a marginally significant difference in past medical history between the two groups $(p=0.05)$.

TABLE 4 Socio-demographic characteristics of pregnant women at enrollment

\begin{tabular}{|c|c|c|c|c|}
\hline Characteristic & Total, n (\%) & Comparison, $\mathrm{n}(\%)$ & Intervention, $\mathrm{n}(\%)$ & p value ${ }^{a}$ \\
\hline \multicolumn{5}{|l|}{ Age (Years) } \\
\hline $15-19$ & $20(13.2)$ & $11(17.5)$ & $9(10.1)$ & \multirow{6}{*}{$0.57^{b}$} \\
\hline $20-24$ & $44(28.9)$ & $18(28.6)$ & $26(29.2)$ & \\
\hline $25-29$ & $38(25.0)$ & $16(25.4)$ & $22(24.7)$ & \\
\hline $30-34$ & 27 (17.8) & $12(19.1)$ & $15(16.9)$ & \\
\hline $35-39$ & $20(13.2)$ & $5(7.9)$ & $15(16.9)$ & \\
\hline$>40$ & $3(1.9)$ & $1(1.6)$ & $2(2.3)$ & \\
\hline
\end{tabular}




\begin{tabular}{|c|c|c|c|c|}
\hline Characteristic & Total, n (\%) & Comparison, $\mathrm{n}(\%)$ & Intervention, $\mathrm{n}(\%)$ & p value ${ }^{a}$ \\
\hline \multicolumn{4}{|l|}{ Education } & \\
\hline No formal education & $11(7.2)$ & $5(7.9)$ & $6(6.7)$ & \multirow{5}{*}{$0.14^{b}$} \\
\hline Primary & 70 (46.1) & $35(55.6)$ & 35 (39.3) & \\
\hline Secondary & $53(34.8)$ & $18(28.6)$ & 35 (39.3) & \\
\hline Higher Secondary & $13(8.6)$ & $5(7.9)$ & $8(8.9)$ & \\
\hline Graduate level and above & $5(3.3)$ & $0(0.0)$ & $5(5.6)$ & \\
\hline \multicolumn{4}{|l|}{ Gravida } & \multirow{3}{*}{0.04} \\
\hline Primipara & $61(40.1)$ & $33(52.4)$ & $28(31.5)$ & \\
\hline Multipara & $91(59.9)$ & $30(47.6)$ & $61(68.5)$ & \\
\hline \multicolumn{4}{|l|}{ Gestational age (weeks) } & \multirow{6}{*}{$0.11^{\mathrm{b}}$} \\
\hline$<21$ & $9(5.9)$ & $3(4.8)$ & $6(6.7)$ & \\
\hline $21-25$ & $18(11.8)$ & $3(4.8)$ & $15(16.9)$ & \\
\hline $26-30$ & $18(11.8)$ & $10(15.9)$ & $8(8.9)$ & \\
\hline 31-35 & $30(19.7)$ & $11(17.5)$ & $19(21.4)$ & \\
\hline$>35$ & $77(50.7)$ & 36 (57.1) & $41(46.1)$ & \\
\hline \multicolumn{4}{|l|}{ BP } & \\
\hline$<160 / 110 \mathrm{mmHg}$ & $116(76.3)$ & $52(82.5)$ & $64(71.9)$ & \multirow{2}{*}{0.13} \\
\hline$\geq 160 / 110 \mathrm{mmHg}$ & $36(23.7)$ & $11(17.5)$ & $25(28.1)$ & \\
\hline \multicolumn{4}{|l|}{ Proteinuria } & \multirow{5}{*}{$0.47^{b}$} \\
\hline+1 & $38(25.0)$ & $16(25.4)$ & $22(24.7)$ & \\
\hline+2 & $23(15.1)$ & $9(14.3)$ & $14(15.7)$ & \\
\hline+3 & $11(7.2)$ & $7(11.1)$ & $4(4.5)$ & \\
\hline Trace/Nil & $80(52.6)$ & $31(49.2)$ & 49 (55.1) & \\
\hline \multicolumn{4}{|l|}{ Have any past medical history? } & \multirow{3}{*}{0.05} \\
\hline Yes & $22(14.5)$ & $5(7.9)$ & 17 (19.1) & \\
\hline No & $130(85.5)$ & $58(92.1)$ & $72(80.9)$ & \\
\hline (n) & $(152)$ & (63) & (89) & \\
\hline \multicolumn{4}{|l|}{ Type of past medical history * } & \\
\hline Chronic HTN & $9(40.9)$ & $1(20.0)$ & $8(47.1)$ & $0.76^{b}$ \\
\hline Diabetes & $6(27.3)$ & $1(20.0)$ & $5(29.4)$ & $0.68^{b}$ \\
\hline Renal disease & $1(4.6)$ & $0(0.0)$ & $1(5.9)$ & $0.58^{b}$ \\
\hline Cardiovascular disease & $1(4.6)$ & $0(0.0)$ & $1(5.9)$ & $0.58^{b}$ \\
\hline Family history of HTN & $3(13.6)$ & $2(40.0)$ & $1(5.9)$ & $0.12^{b}$ \\
\hline $\mathrm{PE} / \mathrm{E}$ & $3(13.6)$ & $1(20.0)$ & 2 (11.8) & $0.56^{b}$ \\
\hline (n) & (22) & (5) & (17) & \\
\hline
\end{tabular}

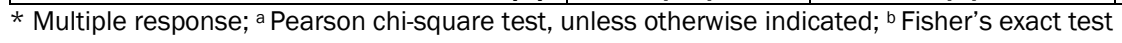

\section{Pre- and Post-Training Tests of Primary Health Care Providers}

All PHC providers' knowledge and perceptions of HDP, PE/E, and anti-hypertensive drugs were assessed before and after their basic trainings in a self-administered questionnaire. A total of 52 providers from comparison facilities and 50 from intervention facilities attended the trainings. Table 5 (following page) lists the pre- and post-training test results of PHC providers, indicating significant improvements in knowledge after the trainings.

Although significant increases in knowledge were seen, knowledge gains were not observed among all providers, however, which indicates need for refresher training or continuous mentoring. For example, 21 percent and 12 percent of providers in comparison and intervention facilities, respectively, did not correctly mention that $\mathrm{PE}$ is a disease with high $\mathrm{BP}(>140 / 90 \mathrm{mmHg})$ and albumin in urine, even after training. 
TABLE 5 Pre- and post-basic training tests results of providers

\begin{tabular}{|c|c|c|c|c|c|c|c|c|c|c|c|c|}
\hline \multirow{3}{*}{\multicolumn{3}{|c|}{ Statement }} & \multicolumn{5}{|c|}{ Comparison $(n=52)$} & \multicolumn{5}{|c|}{ Intervention $(\mathrm{n}=50)$} \\
\hline & & & \multicolumn{2}{|c|}{ Before } & \multicolumn{2}{|c|}{ After } & \multirow{2}{*}{$\begin{array}{c}\text { p- } \\
\text { value }^{a}\end{array}$} & \multicolumn{2}{|c|}{ Before } & \multicolumn{2}{|c|}{ After } & \multirow{2}{*}{$\begin{array}{c}\text { p- } \\
\text { value }\end{array}$} \\
\hline & & & $n$ & $\%$ & $\mathrm{n}$ & $\%$ & & $n$ & $\%$ & $n$ & $\%$ & \\
\hline \multirow{3}{*}{\multicolumn{2}{|c|}{$\begin{array}{l}\text { a) Every woman's BP would } \\
\text { increase during pregnancy }\end{array}$}} & Yes & 12 & 23.1 & 2 & 3.8 & \multirow{3}{*}{$<0.001$} & 11 & 22.0 & 3 & 6.0 & \multirow{3}{*}{$<0.001$} \\
\hline & & No & 38 & 73.1 & 50 & 96.2 & & 38 & 76.0 & 47 & 94.0 & \\
\hline & & Dk & 2 & 3.8 & 0 & 0.0 & & 1 & 2.0 & 0 & 0.0 & \\
\hline \multirow[t]{3}{*}{ b) } & \multirow{3}{*}{$\begin{array}{l}\text { Chronic hypertension is high BP } \\
\text { above } 140 / 90 \mathrm{mmHg} \text { among } \\
\text { pregnant women in any time } \\
\text { before and after pregnancy }\end{array}$} & Yes & 31 & 59.6 & 45 & 86.5 & \multirow{3}{*}{$<0.001$} & 32 & 64.0 & 48 & 96.0 & \multirow{3}{*}{$<0.001$} \\
\hline & & No & 17 & 32.7 & 5 & 9.6 & & 17 & 34.0 & 2 & 4.0 & \\
\hline & & Dk & 4 & 7.7 & 2 & 3.8 & & 1 & 2.0 & 0 & 0.0 & \\
\hline \multirow[t]{3}{*}{ c) } & \multirow{3}{*}{$\begin{array}{l}\text { PE is a condition in pregnancy } \\
\text { with high } \mathrm{BP}(>140 / 90 \mathrm{mmHg}) \\
\text { after } 20 \text { weeks' gestation }\end{array}$} & Yes & 33 & 63.5 & 11 & 21.2 & \multirow{3}{*}{$<0.001$} & 30 & 60.0 & 8 & 16.0 & \multirow{3}{*}{0.052} \\
\hline & & No & 13 & 25.0 & 41 & 78.8 & & 18 & 36.0 & 42 & 84.0 & \\
\hline & & Dk & 6 & 11.5 & 0 & 0.0 & & 2 & 4.0 & 0 & 0.0 & \\
\hline \multirow[t]{3}{*}{ d) } & \multirow{3}{*}{$\begin{array}{l}\mathrm{PE} \text { is a condition in pregnancy } \\
\text { with high } \mathrm{BP}(>140 / 90 \mathrm{mmHg})+ \\
\text { urine albumin after } 20 \text { weeks' } \\
\text { gestation }\end{array}$} & Yes & 30 & 57.7 & 41 & 78.8 & \multirow{3}{*}{$<0.001$} & 20 & 40.0 & 44 & 88.0 & \multirow{3}{*}{$<0.001$} \\
\hline & & No & 20 & 38.5 & 11 & 21.2 & & 30 & 60.0 & 6 & 12.0 & \\
\hline & & Dk & 2 & 3.8 & 0 & 0.0 & & 0 & 0.0 & 0 & 0.0 & \\
\hline e) & Calcium can be provided after 20 & Yes & 21 & 40.4 & 26 & 50.0 & & 14 & 28.0 & 5 & 10.0 & \multirow{3}{*}{$<0.001$} \\
\hline & weeks pregnancy for $\mathrm{PE}$ & No & 24 & 46.2 & 24 & 46.2 & & 33 & 66.0 & 45 & 90.0 & \\
\hline & pre & Dk & 7 & 13.5 & 2 & 3.8 & 017 & 3 & 6.0 & 0 & 0.0 & \\
\hline f) & Loading dose of $\mathrm{MgSO}_{4}$ for & Yes & 33 & 63.5 & 50 & 96.2 & & 35 & 70.0 & 48 & 96.0 & \\
\hline & prevention and treatment of & No & 7 & 13.5 & 1 & 1.9 & $<0.001$ & 14 & 28.0 & 2 & 4.0 & $<0.001$ \\
\hline & $\begin{array}{l}\text { convulsion in eclampsia is } 10 \mathrm{gm} \\
\text { intramuscular injection }\end{array}$ & Dk & 12 & 23.1 & 1 & 1.9 & & 1 & 2.0 & 0 & 0.0 & \\
\hline g) & Pregnant women should not use & Yes & 8 & 15.4 & 12 & 23.1 & & 14 & 28.0 & 8 & 16.0 & \\
\hline & any anti-hypertensive drug to & No & 36 & 69.2 & 40 & 76.9 & $<0.001$ & 35 & 70.0 & 42 & 84.0 & $<0.001$ \\
\hline & col & Dk & 8 & 15.4 & 0 & 0.0 & & 1 & 2.0 & 0 & 0.0 & \\
\hline h) & If a pregnant woman comes in & Yes & 31 & 59.6 & 21 & 40.4 & & 25 & 50.0 & 5 & 10.0 & \\
\hline & ANC visit at 30 weeks and her BP & No & 17 & 32.7 & 30 & 57.7 & & 25 & 50.0 & 45 & 90.0 & \\
\hline & $\begin{array}{l}\text { is } 180 / 115 \text { with albumin in } \\
\text { urine, severe headache and } \\
\text { blurred vision-suffering from } \\
\text { chronic HTN }\end{array}$ & Dk & 4 & 7.7 & 1 & 1.9 & 0.127 & 0 & 0.0 & 0 & 0.0 & $<0.001$ \\
\hline i) & If a pregnant woman attends & Yes & 26 & 50.0 & 21 & 40.4 & & 28 & 56.0 & 8 & 16.0 & \\
\hline & ANC at 12 weeks and BP is $160 /$ & No & 23 & 44.2 & 30 & 57.7 & 0.292 & 19 & 38.0 & 42 & 84.0 & 0.02 \\
\hline & $\begin{array}{l}100 \text { with } n \\
\text { suffering fr }\end{array}$ & Dk & 3 & 5.8 & 1 & 1.9 & & 3 & 6.0 & 0 & 0.0 & \\
\hline j) & If a pregnant woman attends & Yes & 41 & 78.8 & 48 & 92.3 & & 29 & 58.0 & 43 & 86.0 & \\
\hline & ANC at 36 weeks and BP $>140 /$ & No & 8 & 15.4 & 3 & 5.8 & & 18 & 36.0 & 6 & 12.0 & \\
\hline & $\begin{array}{l}90 \mathrm{mmHg} \text { with albumin in urine, } \\
\text { and then one week later her } \\
\text { husband brings her with } \\
\text { convulsion-suffering from } \\
\text { eclampsia }\end{array}$ & Dk & 3 & 5.8 & 1 & 1.9 & $<0.001$ & 3 & 6.0 & 1 & 2.0 & $<0.001$ \\
\hline & & Yes & 23 & 44.2 & 32 & 61.5 & & 8 & 16.0 & 30 & 60.0 & \\
\hline & Alpna metnylaopa can be used & No & 16 & 30.8 & 17 & 32.7 & $<0.001$ & 37 & 74.0 & 18 & 36.0 & 0.04 \\
\hline & & Dk & 13 & 25.0 & 3 & 5.8 & & 5 & 10.0 & 2 & 4.0 & \\
\hline
\end{tabular}

a Stuart-Maxwell test 


\section{Effects of the Intervention}

\section{Provider competence in managing hypertensive disorders of pregnancy}

Almost all PHC providers, in both groups, at baseline and endline knew the correct definition of hypertension ( $\geq 140 / 90 \mathrm{mmHg}$ during pregnancy). Similarly, almost all PHC providers who knew the types of HDP could grade or classify hypertension as mild, moderate, and severe at endline. There was significant knowledge improvement for when to initiate anti-hypertensive drugs, although not enough, among PHC providers in the intervention group (65\%), compared to only 20 percent in the comparison group $(p<0.001)$.

While knowledge of when to administer anti-hypertensive drugs was not conveyed in the Ending Eclampsia project's core intervention, findings show significant improvements. Other variables, such as definition of hypertension, types of HDP, and classification of hypertension, discussed in the project's core intervention did not improve as much, as providers' knowledge of them was already high.

TABLE 6 Intervention effects on provider competencies in managing pregnancy hypertension

\begin{tabular}{|c|c|c|c|c|c|c|c|c|c|}
\hline \multirow{2}{*}{$\begin{array}{l}\text { Provider } \\
\text { Competency }\end{array}$} & \multicolumn{3}{|c|}{ Comparison, n (\%) } & \multicolumn{3}{|c|}{ Intervention, n (\%) } & \multirow[b]{2}{*}{$\begin{array}{c}\text { Mean } \\
\text { Diff }\end{array}$} & \multirow[b]{2}{*}{$\begin{array}{l}\text { NIE } \\
(\%)\end{array}$} & \multirow[b]{2}{*}{ p-value } \\
\hline & Baseline & Endline & Diff & Baseline & Endline & Diff & & & \\
\hline $\begin{array}{l}\text { Defined HTN- } \\
\geq 140 / 90 \mathrm{mmHg} \\
\text { during pregnancy }\end{array}$ & $\begin{array}{c}49 \\
(94.2)\end{array}$ & $\begin{array}{c}45 \\
(91.8)\end{array}$ & -2.4 & $\begin{array}{c}49 \\
(98.0)\end{array}$ & $\begin{array}{c}47 \\
(100.0)\end{array}$ & 2.0 & -0.002 & 4.4 & 0.93 \\
\hline \multicolumn{10}{|l|}{ Knew types of HDP } \\
\hline Chronic HTN & $\begin{array}{c}41 \\
(78.8)\end{array}$ & $\begin{array}{c}35 \\
(71.4)\end{array}$ & -7.4 & $\begin{array}{c}40 \\
(80.0)\end{array}$ & $\begin{array}{c}41 \\
(87.2)\end{array}$ & 7.2 & -0.003 & 14.7 & 0.21 \\
\hline $\begin{array}{l}\text { Gestational } \\
\text { hypertension }\end{array}$ & $\begin{array}{c}30 \\
(57.7) \\
\end{array}$ & $\begin{array}{c}39 \\
(78.0) \\
\end{array}$ & 20.3 & $\begin{array}{c}26 \\
(53.1) \\
\end{array}$ & $\begin{array}{c}45 \\
(95.7) \\
\end{array}$ & 42.6 & 0.063 & 22.3 & 0.07 \\
\hline PE & $\begin{array}{c}52 \\
(100.0)\end{array}$ & $\begin{array}{c}50 \\
(100.0)\end{array}$ & 0.0 & $\begin{array}{c}48 \\
(98.0)\end{array}$ & $\begin{array}{c}47 \\
(100.0)\end{array}$ & 2.0 & 0.009 & 2.0 & 0.32 \\
\hline Severe PE & $\begin{array}{c}25 \\
(48.1) \\
\end{array}$ & $\begin{array}{c}35 \\
(70.0) \\
\end{array}$ & 21.9 & $\begin{array}{c}21 \\
(42.9) \\
\end{array}$ & $\begin{array}{c}34 \\
(72.3) \\
\end{array}$ & 29.4 & -0.153 & 7.5 & 0.58 \\
\hline Eclampsia & $\begin{array}{c}52 \\
(100.0) \\
\end{array}$ & $\begin{array}{c}50 \\
(100.0) \\
\end{array}$ & 0.0 & $\begin{array}{c}48 \\
(98.0)\end{array}$ & $\begin{array}{c}47 \\
(100.0) \\
\end{array}$ & 2.0 & -0.011 & 2.0 & 0.31 \\
\hline \multicolumn{10}{|c|}{ Correctly classified hypertension (HTN) } \\
\hline Mild HTN & $\begin{array}{c}45 \\
(86.5)\end{array}$ & $\begin{array}{c}47 \\
(96.0)\end{array}$ & 9.5 & $\begin{array}{c}46 \\
(91.8)\end{array}$ & $\begin{array}{c}47 \\
(100.0)\end{array}$ & 9.2 & 0.046 & -1.3 & 0.85 \\
\hline Moderate HTN & $\begin{array}{c}45 \\
(86.5) \\
\end{array}$ & $\begin{array}{c}47 \\
(96.0)\end{array}$ & 9.5 & $\begin{array}{c}40 \\
(79.6)\end{array}$ & $\begin{array}{c}46 \\
(97.9) \\
\end{array}$ & 18.3 & -0.026 & 8.8 & 0.30 \\
\hline Severe HTN & $\begin{array}{c}51 \\
(98.1) \\
\end{array}$ & $\begin{array}{c}49 \\
(100.0) \\
\end{array}$ & 1.9 & $\begin{array}{c}50 \\
(100.0) \\
\end{array}$ & $\begin{array}{c}46 \\
(97.9) \\
\end{array}$ & -2.1 & -0.001 & -4.1 & 0.16 \\
\hline $\begin{array}{l}\text { When to initiate } \\
\text { anti-hypertensive }\end{array}$ & $\begin{array}{c}22 \\
(42.3) \\
\end{array}$ & $\begin{array}{c}30 \\
(62.0) \\
\end{array}$ & 19.7 & $\begin{array}{c}15 \\
(30.6) \\
\end{array}$ & $\begin{array}{c}45 \\
(95.7) \\
\end{array}$ & 65.1 & 0.105 & 45.4 & $<0.001$ \\
\hline (n) & (52) & (50) & & $(49)$ & $(47)$ & & & & \\
\hline
\end{tabular}

Diff- difference, $\mathrm{NIE}$ - Net intervention effect, $\mathrm{HTN}$ - hypertension, $\mathrm{MgSO}_{4}$ - magnesium sulphate

\section{Perception and Practice of Anti-Hypertensive Drug Use}

PHC providers' knowledge of specific drug use, namely alpha methyldopa, to control BP during pregnancy significantly improved in both groups (Table 5). About one third of providers in the intervention group prescribed alpha methyldopa at endline, while one sixth in the comparison group did the same (Table 7, following page). Differences in prescribing alpha methyldopa, between baseline and endline in both groups, were not significant. 
TABLE 7 PHC provider perceptions and prescribing practices for anti-hypertensive drugs

\begin{tabular}{|c|c|c|c|c|c|c|c|c|c|}
\hline & \multicolumn{3}{|c|}{ Comparison, n (\%) } & \multicolumn{3}{|c|}{ Intervention, n (\%) } & \multirow[b]{2}{*}{$\begin{array}{l}\text { Mean } \\
\text { Diff }\end{array}$} & \multirow[b]{2}{*}{$\begin{array}{l}\text { NIE } \\
(\%)\end{array}$} & \multirow[b]{2}{*}{$\begin{array}{c}\mathrm{p}- \\
\text { value }\end{array}$} \\
\hline & Baseline & Endline & Diff & Baseline & Endline & Diff & & & \\
\hline $\begin{array}{l}\text { Alpha methyldopa } \\
\text { safety for HDP }\end{array}$ & $18(34.6)$ & $50(100.0)$ & 65.4 & $14(28.6)$ & $47(100.0)$ & 71.4 & -0.301 & 6.0 & 0.53 \\
\hline \multicolumn{10}{|c|}{ What specific drugs are used (could be prescribed) to control BP during pregnancy? } \\
\hline Alpha Methyldopa & $47(90.4)$ & $47(94.0)$ & 4.4 & $35(71.4)$ & $44(93.6)$ & 22.2 & -0.098 & 18.6 & 0.04 \\
\hline Labetalol & $3(5.8)$ & $0(0.0)$ & -5.8 & $9(18.4)$ & $1(2.1)$ & -16.3 & 0.074 & -10.5 & 0.13 \\
\hline Nifedipine & $2(3.8)$ & $3(6.0)$ & 2.8 & $4(8.2)$ & $2(4.3)$ & -3.9 & 0.013 & -6.1 & 0.36 \\
\hline Hydralazine & $0(0.0)$ & $0(0.0)$ & 0.0 & $1(2.0)$ & $0(0.0)$ & -2.0 & 0.010 & -2.0 & 0.31 \\
\hline \multicolumn{10}{|c|}{ Prescribed anti-hypertensive drug during pregnancy } \\
\hline $\begin{array}{l}\text { Alpha } \\
\text { Methyldopa }\end{array}$ & $6(11.5)$ & $8(16.0)$ & 4.5 & $9(18.4)$ & $13(27.7)$ & 9.3 & 0.091 & 4.8 & 0.66 \\
\hline Labetalol & $0(0.0)$ & $2(4.0)$ & 4.0 & $3(6.1)$ & $3(6.4)$ & 0.3 & 0.042 & -3.7 & 0.51 \\
\hline Nifedipine & $2(3.8)$ & $2(4.0)$ & 0.2 & $4(8.2)$ & $0(0.0)$ & -8.2 & 0.002 & -8.3 & 0.14 \\
\hline (n) & (52) & $(50)$ & & (49) & (47) & & & & \\
\hline
\end{tabular}

Diff- difference, NIE- Net intervention effect, $\mathrm{HTN}$ - hypertension, $\mathrm{MgSO}_{4}$ - magnesium sulphate

\section{Provider Practice with Antenatal Care Clients}

Client-provider interactions (CPI) with ANC clients were observed in all facilities, to assess HDP management practices (Table 8). Significant positive changes were observed from baseline to endline among intervention facility providers in hypertension and high BP history-taking $(p<0.05)$ as well as checking for albumin in urine $(p<0.001)$, compared to comparison facilities, yet some provider practices in comparison facilities were significantly better at endline than in intervention facilities. There was a 40 percent increase among comparison providers who advised ANC patients about severe headaches from baseline to endline, compared to a 10 percent increase among intervention providers $(p<0.05)($ Table 8$)$.

As comparison and intervention areas for this anti-hypertensive study were selected within Ending Eclampsia project core intervention areas, some positive changes in provider HDP care practices were observed in both comparison and intervention areas from baseline to endline.

TABLE 8 Effects of intervention on providers practices in managing HDP through CPI

\begin{tabular}{|c|c|c|c|c|c|c|c|c|c|}
\hline \multirow{2}{*}{ Provider Practice } & \multicolumn{3}{|c|}{ Comparison, n (\%) } & \multicolumn{3}{|c|}{ Intervention, n (\%) } & \multirow{2}{*}{$\begin{array}{c}\text { Mean } \\
\text { Diff }\end{array}$} & \multirow{2}{*}{$\begin{array}{l}\text { NIE } \\
(\%)\end{array}$} & \multirow{2}{*}{$\begin{array}{c}\text { p- } \\
\text { value }\end{array}$} \\
\hline & Baseline & Endline & Diff & Baseline & Endline & Diff & & & \\
\hline Took history of HTN/high BP & $\begin{array}{c}6 \\
(14.3) \\
\end{array}$ & $\begin{array}{c}19 \\
(32.2) \\
\end{array}$ & 18.1 & $\begin{array}{c}6 \\
(10.5) \\
\end{array}$ & $\begin{array}{c}38 \\
(54.3) \\
\end{array}$ & 43.8 & 0.098 & 25.8 & 0.03 \\
\hline Took history of PE/E & $\begin{array}{c}0 \\
(0.0)\end{array}$ & $\begin{array}{c}49 \\
(83.1)\end{array}$ & 83.1 & $\begin{array}{c}0 \\
(0.0)\end{array}$ & $\begin{array}{c}58 \\
(82.9)\end{array}$ & 82.9 & -0.028 & -0.2 & 0.98 \\
\hline Took history of heart disease & $\begin{array}{c}0 \\
(0.0) \\
\end{array}$ & $\begin{array}{c}5 \\
(8.5) \\
\end{array}$ & 8.5 & $\begin{array}{c}0 \\
(0.0) \\
\end{array}$ & $\begin{array}{c}6 \\
(8.6) \\
\end{array}$ & 8.6 & -0.002 & 1.0 & 0.98 \\
\hline Took anxiety, depression history & $\begin{array}{c}0 \\
(0.0)\end{array}$ & $\begin{array}{c}5 \\
(8.5)\end{array}$ & 8.5 & $\begin{array}{c}0 \\
(0.0)\end{array}$ & $\begin{array}{c}5 \\
(7.1)\end{array}$ & 7.1 & -0.010 & -1.3 & 0.81 \\
\hline Measured client BP & $\begin{array}{c}34 \\
(81.0) \\
\end{array}$ & $\begin{array}{c}58 \\
(98.3) \\
\end{array}$ & 17.7 & $\begin{array}{c}40 \\
(70.2)\end{array}$ & $\begin{array}{c}70 \\
(100.0) \\
\end{array}$ & 29.8 & -0.045 & 12.5 & 0.12 \\
\hline Checked urine albumin & $\begin{array}{c}1 \\
(2.4)\end{array}$ & $\begin{array}{c}8 \\
(13.6) \\
\end{array}$ & 11.2 & $\begin{array}{c}0 \\
(0.0)\end{array}$ & $\begin{array}{c}59 \\
(84.3) \\
\end{array}$ & 84.3 & 0.375 & 73.1 & $<0.001$ \\
\hline Advised on severe headache & $\begin{array}{c}13 \\
(31.0)\end{array}$ & $\begin{array}{c}42 \\
(71.2)\end{array}$ & 40.2 & $\begin{array}{c}19 \\
(33.3)\end{array}$ & $\begin{array}{c}30 \\
(42.9)\end{array}$ & 9.6 & -0.158 & -30.7 & 0.02 \\
\hline Advised on blurred vision & $\begin{array}{c}2 \\
(4.8)\end{array}$ & $\begin{array}{c}37 \\
(62.7)\end{array}$ & 57.9 & $\begin{array}{c}6 \\
(10.5)\end{array}$ & $\begin{array}{c}31 \\
(44.3)\end{array}$ & 33.8 & -0.094 & -24.2 & 0.03 \\
\hline (n) & (42) & (59) & & (57) & (70) & & & & \\
\hline
\end{tabular}




\section{Diagnosis and Management}

Providers' diagnoses of patients upon their enrollment, their service provision, and management of HDP were assessed. Table 9 demonstrates that HDP classifications among patients were similar in both facility groups. Only moderate to severe hypertensive patients were enrolled in the study for management and follow up. Among women with moderate to severe hypertension who required anti-hypertensive drugs upon diagnosis, all women in the intervention group received alpha methyldopa, while none in the comparison group did $(p<0.001)$. Moreover, 45 percent of women with severe PE in the intervention group received a loading dose of $\mathrm{MgSO}_{4}$ upon diagnosis, compared to 38 percent in the comparison group $(\mathrm{p}<0.001$; Table 9).

Nearly all (97\%) women with moderate to severe hypertension in all facilities were referred to other facilities for further management. Among referred patients, 62 percent of those from intervention facilities and 51 percent from comparison facilities presented for further treatment at referral facilities, which indicates that a substantial percentage of women did not complete the referral process and required further medical attention.

TABLE 9 Hypertension diagnosis at enrollment, services received, and management in pregnancy

\begin{tabular}{|c|c|c|c|c|}
\hline Indicator & $\begin{array}{l}\text { Total } \\
\text { n (\%) }\end{array}$ & $\begin{array}{c}\text { Comparison } \\
n(\%)\end{array}$ & $\begin{array}{l}\text { Intervention } \\
\text { n (\%) }\end{array}$ & $p$-value \\
\hline \multicolumn{5}{|l|}{ Diagnosis at enrollment } \\
\hline Chronic HDP & $11(7.2)$ & $3(4.8)$ & $8(8.9)$ & \multirow{4}{*}{0.75} \\
\hline Gestational HTN & $66(43.4)$ & $29(46.0)$ & $37(41.6)$ & \\
\hline $\mathrm{PE}$ & $26(17.1)$ & $10(15.8)$ & $16(17.9)$ & \\
\hline Severe PE & $49(32.2)$ & $21(33.3)$ & $28(31.5)$ & \\
\hline Did service providers provide medicine & $145(95.4)$ & $56(88.9)$ & $89(100.0)$ & $<0.001^{b}$ \\
\hline \multicolumn{5}{|l|}{ Service providers supplied medicine from facilities* } \\
\hline Alpha Methyldopa & $89(58.6)$ & $0(0.0)$ & $89(100.0)$ & $<0.001^{b}$ \\
\hline Calcium & $67(44.1)$ & $42(66.7)$ & $25(28.1)$ & $<0.001$ \\
\hline Iron & $81(53.3)$ & $43(68.3)$ & $38(42.7)$ & 0.002 \\
\hline Injection $\mathrm{MgSO}_{4}$ loading dose & 64 (42.1) & 24 (38.1) & $40(44.9)$ & 0.40 \\
\hline \multicolumn{5}{|l|}{ Provider informed how to take medicine* } \\
\hline Need to take every day until delivery & $62(40.8)$ & $22(34.9)$ & $40(44.9)$ & 0.22 \\
\hline Purchase from pharmacy if cannot re-fill at facility & $5(3.3)$ & $3(4.8)$ & $2(2.3)$ & $0.39^{\mathrm{b}}$ \\
\hline Return if any side effects & $16(10.5)$ & $3(4.8)$ & $13(14.6)$ & $0.06^{b}$ \\
\hline Take single dose and go to higher facility & $91(59.8)$ & $6(9.5)$ & $85(95.5)$ & $<0.001$ \\
\hline $\begin{array}{l}\text { Respondent had both } \mathrm{MgSO}_{4} \text { loading dose and alpha } \\
\text { methyldopa }\end{array}$ & $46(30.3)$ & $6(9.5)$ & $40(44.9)$ & $<0.001$ \\
\hline $\begin{array}{l}\text { Did provider give referral slip and instruct to go to } \\
\text { higher facility }\end{array}$ & $147(96.7)$ & $61(96.8)$ & $86(96.6)$ & $0.57^{\mathrm{b}}$ \\
\hline (n) & (152) & (63) & (89) & \\
\hline \multicolumn{5}{|l|}{ Did respondent go to referral facility } \\
\hline Yes & $84(57.1)$ & $31(50.8)$ & $53(61.6)$ & \multirow{2}{*}{0.19} \\
\hline No & $63(42.9)$ & $30(49.2)$ & $33(38.4)$ & \\
\hline (n) & (147) & (61) & (86) & \\
\hline
\end{tabular}

* Multiple response, a Pearson chi-square test, unless otherwise indicated; ${ }^{b}$ Fisher's exact test 


\section{Pregnancy Outcomes for Women with Hypertensive Disorders in Pregnancy}

Women in both groups were followed throughout their pregnancies, to assess their pregnancy outcomes. Between the two groups there was no significant difference in gestational age, mode or place of delivery, assistance during delivery, and maternal outcomes. About four fifths of all women with HDP delivered at 36 weeks or later, while a small proportion, in all groups, delivered before 33 weeks (Table 10). No maternal deaths occurred in either group among those who sought services from PHC facilities.

There were significant differences in infants' outcomes $(p<0.001)$. More infants died in the comparison group (14\%; $n=9)$ than in the intervention group ( $3 \% ; n=3)$. Further analysis shows that hypertensive women who received alpha methyldopa were 1.36 times more likely to deliver a live infant than to women who did not receive alpha methyldopa during pregnancy (AOR:1.36, 95\% Cl:0.30-5.43).

TABLE 10 Pregnancy outcomes among hypertensive women

\begin{tabular}{|c|c|c|c|c|}
\hline Indicator & Total, n (\%) & Comparison, $\mathrm{n}(\%)$ & Intervention, $\mathrm{n}(\%)$ & p-value \\
\hline \multicolumn{5}{|c|}{ Gestational age at delivery (week) } \\
\hline$<33$ & $4(2.6)$ & $3(4.8)$ & $1(1.1)$ & \multirow{3}{*}{$0.49^{b}$} \\
\hline $33-36$ & $24(15.8)$ & $10(15.9)$ & $14(15.7)$ & \\
\hline$>36$ & $124(81.6)$ & $50(79.3)$ & $74(83.2)$ & \\
\hline \multicolumn{5}{|l|}{ Mode of delivery } \\
\hline C-section & $74(48.6)$ & $29(46.0)$ & $45(50.6)$ & \multirow{2}{*}{0.58} \\
\hline Normal delivery & 78 (51.4) & $34(54.0)$ & $44(49.4)$ & \\
\hline \multicolumn{5}{|l|}{ Place of delivery } \\
\hline Home & $30(19.7)$ & $9(14.3)$ & $21(23.6)$ & \multirow{3}{*}{0.27} \\
\hline Government hospital & $63(41.5)$ & $30(47.6)$ & $33(37.1)$ & \\
\hline Private hospital & $59(38.8)$ & $24(38.1)$ & $35(39.3)$ & \\
\hline \multicolumn{5}{|l|}{ Who assisted in delivery ${ }^{*}$} \\
\hline Doctors & $88(57.9)$ & $31(49.2)$ & $57(64.0)$ & 0.07 \\
\hline Nurses & $106(69.7)$ & $45(71.4)$ & $61(68.5)$ & 0.70 \\
\hline FWV & $15(9.9)$ & 7 (11.1) & $8(8.9)$ & 0.58 \\
\hline Trained TBA & $6(3.9)$ & $2(3.2)$ & $4(4.5)$ & $0.68^{b}$ \\
\hline Untrained TBA & $19(12.5)$ & $6(9.5)$ & $13(14.6)$ & 0.35 \\
\hline Relatives/Neighbor & $30(19.7)$ & $14(22.2)$ & $16(17.9)$ & 0.41 \\
\hline \multicolumn{5}{|l|}{ Maternal outcome } \\
\hline Alive & $152(100.0)$ & $63(100.0)$ & $89(100.0)$ & - \\
\hline \multicolumn{5}{|l|}{ Newborn outcome } \\
\hline Alive & $130(85.5)$ & $54(85.7)$ & $76(85.4)$ & \multirow{3}{*}{$0.001^{b}$} \\
\hline Not alive & $12(7.9)$ & $9(14.3)$ & $3(3.4)$ & \\
\hline Sick & $10(6.6)$ & $0(0.0)$ & $10(10.2)$ & \\
\hline$(\mathrm{n})$ & (152) & (63) & (89) & \\
\hline \multicolumn{5}{|c|}{ Women gestational age (week) at delivery (newborn was not alive) } \\
\hline$<33$ & $\mathbf{1}(\mathbf{8 . 3 )}$ & 1(11.1) & $0(0.0)$ & \multirow{3}{*}{$0.80^{\mathrm{b}}$} \\
\hline 33-36 & $3(25.0)$ & $2(22.2)$ & 1(33.3) & \\
\hline$>36$ & $8(66.7)$ & 6(66.7) & 2(66.7) & \\
\hline (n) & $(12)$ & $(9)$ & $(3)$ & \\
\hline \multicolumn{5}{|c|}{ Women gestational age (week) at delivery (newborn was sick) } \\
\hline$<33$ & $0(0.0)$ & $0(0.0)$ & $0(0.0)$ & \multirow{3}{*}{-} \\
\hline 33-36 & $2(20.0)$ & $0(0.0)$ & $2(20.0)$ & \\
\hline$>36$ & $8(80.0)$ & $0(0.0)$ & $8(80.0)$ & \\
\hline$(n)$ & (10) & $(0)$ & $(10)$ & \\
\hline
\end{tabular}

* Multiple response, a Pearson chi-square test, unless otherwise indicated; ${ }^{b}$ Fisher's exact test 


\section{Facility Readiness for Services to Hypertensive Pregnant Women}

The pre-intervention assessment revealed similarities with all facilities' equipment availability, with shortages in functional sphygmomanometers and stethoscopes, as well as unexpired dipsticks for urine albumin tests (Table 11). There were virtually no commodities (alpha methyldopa and $\mathrm{MgSO}_{4}$ injections) at any facilities at baseline. At endline, equipment and commodities were available and functional in all facilities-except alpha methyldopa, which was only available in intervention facilities.

TABLE 11 Effects of intervention on facility readiness for managing HDP

\begin{tabular}{|c|c|c|c|c|c|c|c|c|c|}
\hline & \multicolumn{3}{|c|}{ Comparison, n (\%) } & \multicolumn{3}{|c|}{ Intervention, n (\%) } & \multirow{2}{*}{$\begin{array}{l}\text { Mean } \\
\text { Diff }\end{array}$} & \multirow{2}{*}{$\begin{array}{l}\text { NIE } \\
(\%)\end{array}$} & \multirow{2}{*}{$\begin{array}{c}\mathrm{p}- \\
\text { value }\end{array}$} \\
\hline & Baseline & Endline & Diff & Baseline & Endline & Diff & & & \\
\hline \multicolumn{10}{|l|}{ Diagnosis Equipment } \\
\hline $\begin{array}{l}\text { Presence of functional } \\
\text { sphygmomanometer }\end{array}$ & $17(73.9)$ & $23(100.0)$ & 26.1 & $24(77.4)$ & $31(100.0)$ & 22.6 & 0.017 & -3.5 & 0.77 \\
\hline $\begin{array}{l}\text { Presence of functional } \\
\text { stethoscope }\end{array}$ & $20(87.0)$ & $23(100.0)$ & 13.0 & $24(77.4)$ & $31(100.0)$ & 22.6 & -0.047 & 9.6 & 0.38 \\
\hline $\begin{array}{l}\text { Presence of unexpired } \\
\text { dipstick }\end{array}$ & $2(8.7)$ & $23(100.0)$ & 91.3 & $2(6.5)$ & $31(100.0)$ & 93.5 & 0.010 & 2.2 & 0.76 \\
\hline \multicolumn{10}{|l|}{ Medicines } \\
\hline $\begin{array}{l}\text { Presence of alpha } \\
\text { methyldopa }\end{array}$ & $0(0.0)$ & $1(4.3)$ & 4.3 & $0(0.0)$ & $31(100.0)$ & 100.0 & 0.478 & 95.7 & $<0.001$ \\
\hline $\begin{array}{l}\text { Presence of } \mathrm{MgSO}_{4} \\
\text { loading dose }(10 \mathrm{gm})\end{array}$ & $1(4.2)$ & $23(100.0)$ & 95.8 & $0(0.0)$ & $31(100.0)$ & 100.0 & -0.021 & 4.3 & 0.25 \\
\hline (n) & (23) & (23) & & (31) & (31) & & & & \\
\hline
\end{tabular}

\section{Antenatal Care Utilization and Hypertension in Pregnancy Detection}

Service statistics from all study facilities were collected each month. Baseline data of ANC service utilization were collated for three months prior to the intervention, and then throughout the 15 months of the intervention. A high proportion of women, in all facilities, and all time periods, had BP measured. In intervention facilities, 10 percent more women had urine tests for albumin, per national standards, during the intervention than at baseline, which was significantly greater than the change in comparison facilities. Service providers cited lack of toilet facilities at PHC facilities and satellite clinics, provider negligence in choosing to whom to offer services, and client refusals to explain lack of urine testing.

Significantly more women were detected with elevated BP in the intervention group, when comparing baseline and intervention periods (Table 12 and figures 3 to 7, Appendix D; monthly detection of moderate to severe hypertension in ANC visits at all facilities is provided in Figure 8 in Appendix D).

TABLE 12 Service statistics for ANC utilization and proportion of HDPs detected, all data periods

\begin{tabular}{|l|c|c|c|c|c|c|c|c|c|}
\hline \multirow{2}{*}{ Indicator } & \multicolumn{3}{|c|}{ Comparison } & \multicolumn{3}{c|}{ Intervention } & NIE & Mean \\
\cline { 2 - 9 } & Baseline & Study & $\begin{array}{c}\% \\
\text { Change }\end{array}$ & Baseline & Study & $\begin{array}{c}\% \\
\text { Change }\end{array}$ & p value \\
\hline $\begin{array}{l}\text { \# of ANC visits, per month } \\
\text { (new and repeat contacts) }\end{array}$ & 2,580 & 2,379 & -8.5 & 2,676 & 2,679 & 0.1 & 8.6 & -1.88 & 0.02 \\
\hline $\begin{array}{l}\text { \#/\% of women in ANC } \\
\text { contacts BP measured }\end{array}$ & $\begin{array}{c}2,472 \\
(95.8 \%)\end{array}$ & $\begin{array}{c}2,364 \\
(99.4 \%)\end{array}$ & -4.6 & $\begin{array}{c}2,608 \\
(97.5 \%)\end{array}$ & $\begin{array}{c}2,569 \\
(95.9 \%)\end{array}$ & -1.5 & 3.1 & -1.80 & 0.03 \\
\hline $\begin{array}{l}\text { \#/\% of women in ANC } \\
\text { checked for urine albumin }\end{array}$ & $\begin{array}{c}582 \\
(22.5 \%)\end{array}$ & $\begin{array}{c}524 \\
(22.0 \%)\end{array}$ & -11.0 & $\begin{array}{c}1,532 \\
(57.2 \%)\end{array}$ & $\begin{array}{c}1,779 \\
(67.4 \%)\end{array}$ & 13.9 & 24.9 & 2.79 & $<0.001$ \\
\hline $\begin{array}{l}\text { \#/\% of women in ANC } \\
\text { detected with elevated BP }\end{array}$ & $\begin{array}{c}31 \\
(1.2 \%)\end{array}$ & $\begin{array}{c}37 \\
(1.5 \%)\end{array}$ & 18.1 & $\begin{array}{c}23 \\
(0.9 \%)\end{array}$ & $\begin{array}{c}30 \\
(1.1 \%)\end{array}$ & 24.4 & 6.3 & -0.05 & 0.03 \\
\hline
\end{tabular}




\section{Survivors' Experiences}

Researchers conducted in-depth interviews (IDIs) at endline with postpartum women who survived PE/E, at both intervention $(n=13)$ and comparison sites $(n=7)$, to understand their perceptions and experiences of their own hypertension or $\mathrm{PE} / \mathrm{E}$, and the services they received.

\section{Perceptions of Hypertension in Pregnancy, Pre-Eclampsia or Eclampsia, and Their Care}

Women in both study areas have similar ANC views and health-seeking behaviors, mostly visiting a health facility for normal check ups at later stages of pregnancy. A few women visited a facility for symptoms such as headache, dizziness, blurred vision, abdominal pain, or fever. Some women had a severe headache or blurred vision but did not visit a health facility because they thought they were normal pregnancy phenomena and that the symptoms would dissipate with rest. Many women do, however, correlate headaches and dizziness with high BP.

More than half of interviewed women realized their HDP only at the end of the pregnancy, when informed by a service provider, not recognizing HDP's onset. About one fourth of patients in both groups understood that hypertension could develop during pregnancy but knew no signs nor symptoms. Women were not aware of PE/E specifically but knew of potential pregnancy complications such as convulsions and bleeding.

"I went to the nearby health facility at seventh month of my pregnancy. It was my second pregnancy. I had no problems in my first pregnancy. You know, there are always some problems when you got pregnant, this is normal thing. You want to have a child...no problem, it may not happen. Apa [service provider] told me that my pressure is about 160, which is too high. I had severe headache before, but I never come to this health facility."

Survivor, 21 years old, multigravida, Intervention Area

"I have taken antenatal care services once at ninth month of my pregnancy. I went to nearby Jaforgonj Family Welfare Center [PHC facility], Pervin Apa [FWV] measured my blood pressure and said my pressure is high. She gave me a medicine to take, administered injections in my buttock. Then, she referred me to the Cumilla Medical College and Hospital [tertiary referral hospital]."

Survivor, 28 years old, multigravida, Intervention Area

"At the last stage of my pregnancy, when I went to Balla Family Welfare Center, I got to know that my blood pressure is high. I don't know how much... I had no serious problems during the pregnancy period but always felt dizzy. Apa [service provider] told me my pressure is too high and I need some injection...visit...a physician or higher facility. She gave me two injections. There were four injection ampules. I don't know the name of injection. Then she referred me to District Hospital, Tangail."

Survivor, 22 years old, primigravida, Comparison Area

\section{Women's Responses to Referrals}

Most pregnant women in both groups visited referral facilities as a result of provider referral. A few referred women did not complete their referral processes and stayed home, in the belief that they felt well. Women who did not complete their referrals stated that they would visit a referral facility only if symptoms worsened. Some women believe in local, traditional medicines and visit health care facilities only for a severe problem.

"In the eighth month of my pregnancy, the doctor at Family Welfare Center told me that my blood pressure is high. She also...gave medicines for high pressure. I do not know the name of medicine. She also administered injection in my waists. She told me to go Burichong Upazila Health Center for better management...I didn't go anywhere; it is too far. I stayed at home. I had labor pain at home and went to a local doctor."

Survivor, 21 years old, multigravida, Intervention Area 
"From Elenga UH\&FWC they referred me to Tangail District Hospital. My parent took me there immediately. I had high blood pressure. They prescribed me medication for high blood pressure. When I started feeling better, they told me that my physical condition is alright. They told my father to take me home. Then I came back." Survivor, $\mathbf{2 8}$ years old, primigravida, Comparison Area

“Initially, I didn't visit any doctor. I took homeo[pathic] medicine for having normal delivery, but later went to Shalla Family Welfare Center, where I got to know my pressure is high, and they referred me after primary treatment. I was admitted at Tangail District Hospital and had 'caeser' [cesarean section] there." Survivor, 22 years old, primigravida, Comparison Area

\section{Women's Perceptions of Service Provider Behaviors and Care}

Most women, in both study areas, reported high satisfaction of care and that their providers exhibited respectful attitudes towards them. Women stated that they receive adequate services from government PHC and referral facilities. A few women did mention that they visited a private clinic instead of a public referral facility because they believe doctors are not always available at government facilities. Women stated that service providers did not perform urine tests when they found high BP-they just refer.

"I had severe labor pain at night but did not deliver in the whole morning, even. Then, I went to Sadar Hospital [public] on the day at three p.m. Doctor was unavailable there, so they said they can't do delivery without doctor and asked me to take Mirjapur Hospital [private medical college]. My family thought it is too far from here and...can't take me there during this critical time. So, they searched for a clinic nearer to us and we went to doctor's [private] clinic and had cesarean section there."

Survivor, 22 years old, primigravida, Comparison Area

"Service providers from Family Welfare Center were good. When I went there, no one was in the Center, but while they were informed about a patient and within half an hour, they attended me. They checked my pressure several times, with some intervals, and then she referred me to District Hospital; they told me that my pressure is high and need injection before going to District Hospital. After administering injection, I went to a clinic and had cesarean delivery there. Nurses of the clinic were very good, even they came to my home after delivery for follow up."

Survivor, 22 years old, primigravida, Control Area

"The Family Welfare Visitor was modest and helpful. She prescribed medicines, explained me about the problems may I have. She told me about the regularity of taking [blood] pressure drug."

Survivor, 19 years old, multigravida, Intervention Area

"The services of FWC (PHC facility) was very good. I have not spent any extra money."

Survivor, 21 years old, multigravida, Intervention Area

\section{Women's Perceptions of Anti-Hypertensives and Provider Counseling}

Women in both groups had minimum awareness of anti-hypertensive drugs. They mostly depend upon service provider recommendations. Interviewed women did not know the name of alpha methyldopa, or its use as an anti-hypertensive drug, particularly women in the intervention group. Women explained that providers offer minimum information when making recommendations to clients. Women said that providers also did not communicate their urine test results or BP measurements to them.

"I have taken ANC services once at ninth month of my pregnancy. I went to nearby Jaforgonj Family Welfare Center-Family Welfare Visitor measured my pressure and said my pressure is high. She gave a medicine to take, administered injections in my buttocks. Then, she referred me to the Cumilla Medical College and Hospital. She didn't tell much, just said 'don't wait, go quickly.'”

Survivor, 30 years old, Intervention Area 


\section{Views of Policy-Makers, Program Managers and Other Stakeholders}

Researchers conducted IDIs at endline with eight policy-makers and other stakeholders, as well as 10 program managers, in both study areas, on their views and opinions of anti-hypertensive drugs.

\section{Anti-Hypertensive Drug Policy}

Most program managers, from both groups, stated that the government should allow PHC providers to provide anti-hypertensive drugs because it is a necessary part of the course of treatment for $P E / E$ that is missing. They also mentioned delays in their patients reaching referral facilities after their referrals. Some women do not complete their referrals and return home, remaining untreated for high BP unless they are provided $\mathrm{MgSO}_{4}$ prior to referral. Most program managers expressed the need for changing the antihypertensive drug policy, although a few believe PHC providers need more training and supervision, with some restrictions. A few also mentioned allowing other anti-hypertensive drugs, not only alpha methyldopa.

"Yes, they should be allowed because huge number of pregnant mothers go to local health care facilities rather than the higher health care facilities to receive antenatal care service. So, if the PHC service providers can identify hypertension, pre-eclampsia, eclampsia and provide them with the possible treatment at the root level before referring to higher facility, it would reduce the damage that might have due to treatment delay from primary health care to referral center and mother and child morbidity and mortality will reduce to a great extent."

Sub-District Program Manager, Intervention area

"We are procuring magnesium sulphate for the primary health care facilities, and we have already included magnesium sulphate in our operational plan 2017 to 2022. Regarding anti-hypertensive, we are waiting for your study results. After getting your study results, we will go further."

Central Policy-Maker and Implementer, DGFP

"I think the policy needs to be changed, we can approve the primary health care providers for prescribing a specific drug, specific dose and for a specific time duration."

District Program Manager, Intervention Area

"As I have mentioned before, after ensuring their skills of measuring blood pressure, identifying pre-eclampsia or eclampsia and prescribing drug they can be allowed for this task. Mentorship is also needed to verify if works are being done accordingly, if yes, they are found efficient then primary health care providers would be allowed to prescribe anti-hypertensive drug."

Sub-District Program Manager, Comparison Area

"If BMRC gives permission, I think it would be better to administer labetalol instead of methyl dopa, because labetalol reduces the pressure quickly and methyl dopa takes some time... However, they need training to understand at which condition they will provide and to which amount. Sometimes even the doctors go on giving two, three, four doses if the pressure doesn't come down. Alpha methyl dopa can cause fluid retention and in that case anti-hypertensive doesn't work. Even our doctors can't administer it properly-l'm speaking very frankly. Hence, when we are giving it to the Family Welfare Visitor, SACMO, and nurse/midwives, we need to give them a dosage limit which they shouldn't cross. In that case, there won't be a problem."

Former OGSB Official

“There's a procurement policy of the government. Injection magnesium sulphate procurement policy has been adopted. This drug we have listed in our operational plan. We've already recommended its use though we are waiting for your results. About anti-hypertensive drugs, we are thinking. National Technical Committee permitted to do research about Sardopa [alpha methyldopa] using by the primary health care provider and Population Council is conducting it. We are waiting for your report to see the results."

Central Policy-Maker and Implementer, DGFP 


\section{Opinions of Task Sharing with Primary Health Care Providers}

All interviewed program managers stated that this intervention could have significant impacts in reducing maternal deaths. Community members first visit PHC facilities for services, and if PHC providers are equipped with appropriate knowledge and skills recommended for anti-hypertensive drug provision, and then refer women to higher levels of care, deaths due to PE/E can be reduced. Program managers emphasized the delays in patients reaching referral facilities as well as PHC providers' roles in identifying and referring patients in a timely manner. Most Ob/Gyn professionals interviewed are in favor of task sharing, while government policy-makers would like to wait for study results.

The Directorate General of Health Services (DGHS) supplies anti-hypertensive drugs to secondary and tertiary facilities, but it is not clear whether PHC providers such as nurses and midwives are allowed to prescribe them.

"Currently, we don't have anti-hypertensive at all facilities, we have to purchase it. Communitybased Health Care gives us some medicines, I don't know whether they're supplying it. But we only have magnesium sulphate. I have it in my mind that l'd add it during revision."

Policy-Maker and Implementer, DGHS

"Government needs to supply where they are supposed to supply. Mainly, the government should step forward. Why can't they? The drug is unbelievably cheap, there's no reason not to afford it. So, if we want to attain our Sustainable Development Goal targets, our first target would have to be point out these things. Now we're wanting to increase the number of institution deliveries, but for that we need to make the institutions right in the first place. If we don't get doctors there, we can train the FMVs and SACMOs to give certain injections and medications to save the mothers. Even this will be a lot. Some works are being done at the MCWC level, but at the union level they only refer. But at some places in the community level good deliveries are being done. But they need to be trained up. We need to train them to check the blood pressure, weight, anemia since the early pregnancy. We need to target these small things. If we can teach them to give antihypertensive drug, calcium, check the urine albumin, creatinine level, then we can make much progress."

Former OGSB Official, Bangladesh

"Obviously, it would help, because pregnant women go to the Upazila Health Center or higher health care centers much later. I think if there is antenatal care, postnatal care follow up center nearby, then the mothers will be able to go there primarily. I think most of them go to primary health care centers, as it's not possible for many to go to higher health care centers due to transport, communication system, and other reasons. It's also difficult to transfer pregnant mothers easily, so if the anti-hypertensive drug could be prescribed at the nearby community level, then the mothers could go there easily, though the patient should be referred to higher facility along with this."

Program Manager, Intervention Area

Program managers in comparison areas are also in favor of training PHC providers to prescribe antihypertensive drugs. These program managers believe that if PHC providers can be trained on antihypertensive use, it will be more efficacious, as they now only identify and refer, although they are allowed to administer an $\mathrm{MgSO}_{4}$ injection.

"Yes, I did participate in the training on anti-hypertensive drug. Two doctors came as trainers. They explained everything beautifully, with hands on training. And, after the training, we are seeing that those who have received the training can identify hypertension, eclampsia, and pre-eclampsia. They are doing follow up and referring the patients. They are continuing these activities. I think, with training they can prescribe anti-hypertensive drug to the pregnant women."

Sub-District Program Manager, Comparison Area 
"When a patient comes to the sub-district level, there may not be a doctor. In that case, as the primary health care providers are trained, they can give one alpha methyldopa and refer, it wouldn't harm the patient."

Deputy Program Manager

“This intervention is very appropriate, because if our grassroot level isn't conscious, if patients are not referred from there, then patients will only come to us at the very end. So, if we want to prevent, we have to start from the beginning. So, people who are working at the grassroot, they have received special training. And they are medical professionals, they are not lay people. So, they could grasp the training very easily, and they could understand the problem. And, as they face the problem first, they could understand which way is better. They've earned our faith because of our well training. Later, when I visited, I saw them working. So, I think it would be good if they can prescribe anti-hypertensive drug, magnesium sulphate, and then refer to higher level. And if patients aren't referred from grassroot level, then prevention is never possible, we will get the patient [too] late to intervene."

Former OGSB Official

\section{Opinions on Scaling up the Intervention}

Policy-makers, stakeholders, and program managers assert that reductions in maternal deaths due to PE/E require implementation of multiple initiatives. All health system informants suggested that $\mathrm{MgSO}_{4}$ and antihypertensive drug interventions should be scaled up in other parts of the country, as PE/E is a major cause of preventable maternal deaths in Bangladesh.

“Obviously. If this program is expanded to the entire country by government, then huge number of pre-eclampsia, eclampsia patients will be identified, and the primary health care providers can provide primary care and refer the severe patients to higher facility. This will lower the mother and child morbidity and mortality rate."

Sub-District Program Manager, Intervention Area

\section{Supply and Procurement of Anti-Hypertensive Drugs}

The Directorate General of FP does not supply alpha methyldopa to facilities, but DGHS has been supplying it to UHCs and DHs. According to stakeholders and program managers, the government should ensure availability of this drug in every health facility.

"Locally, we local authorities cannot purchase anti-hypertensive drugs. Government should make this available."

Sub-District Program Manager, Comparison Area 


\section{Discussion}

This implementation science, within the greater Ending Eclampsia project, tested the feasibility of training PHC providers (FWVs, SACMOs, nurses) to detect HDPs, manage moderate to severe HDP with a single $500 \mathrm{mg}$ dose of alpha methyldopa, and administer $\mathrm{MgSO}_{4}$ in cases of severe $\mathrm{PE} / \mathrm{E}$, and refer patients for continuing care. The results of this study may be affected by the Ending Eclampsia PHC PE/E core intervention that was implemented previously in this study's intervention and comparison areas. PHC providers in comparison sites had already been trained to detect of high $\mathrm{BP}$ and administer $\mathrm{MgSO}_{4}$, which may have influenced some of the positive trends in comparison facilities.

Despite demands on the public health system to meet new and future challenges, skill deficits within the health workforce are apparent (DeCorby et al 2018, Gebbie et al 2005). WHO suggests task sharing with lower level service providers when a workforce is insufficient (WHO 2008, 2012, 2017). This study demonstrates the potential of PHC provider task sharing for anti-hypertensive drug prescription. PHC providers at intervention facilities were able to correctly measure BP, classify it, provide a single dose of alpha methyldopa, and refer pregnant women in a timely manner, after capacity-building activities provided by the Ending Eclampsia project.

In this study improvements in anti-hypertensive drug knowledge were similar for all sites, suggesting the effects of the core Ending Eclampsia PHC PE/E intervention. Most providers at endline could classify hypertension as mild, moderate, and severe. Providers' knowledge of when to initiate anti-hypertensive drugs significantly improved in the intervention group, compared to the comparison group, although some improvements were also evident in the comparison group.

A recent study linking DHS and facility readiness in sub-Saharan Africa showed particularly poor abilities for managing HDP in pregnancy that indicate that BP measurement alone may not be adequate for quality care (Kanyangarara et al 2017). Results from this study suggest that concomitant training on PE/E and anti-hypertensive drugs, such as administering $\mathrm{MgSO}_{4}$ to severe $\mathrm{PE} / \mathrm{E}$ patients, is much better than $\mathrm{PE} / \mathrm{E}$ training by itself. Simple interventions during pregnancy can have considerable impacts on important mortality outcomes (Hodgins et al 2016). An additional service component such as anti-hypertensive drug prescription can be incorporated within current service delivery models (Mammaro et al 2009, Hodgins et al 2018). Facility readiness must be confirmed in advance by ensuring availability of intramuscular injections of $\mathrm{MgSO}_{4}$, dipsticks for urine tests, BP machines, and stethoscopes (RCOG 2010).

This study's findings show almost universal BP measurement, but no significant increase in urine analysis for albumin. Provider practices for BP measurement and urine analysis, for all clients, must also be improved. A nationally representative study in Afghanistan showed similar findings, with not all women having BP and proteinuria checked when needed (Ansari et al 2019). A challenge for testing urine for albumin is a lack of toilets at facilities or their satellite clinics.

Challenges identified in this study that must be addressed include providers' determinations of whom to offer testing to, as well as patients' refusals. Provider motivation and monitoring are important components as well (WHO 2011). Not every provider detected, or received for care, a pregnant woman with HDP who

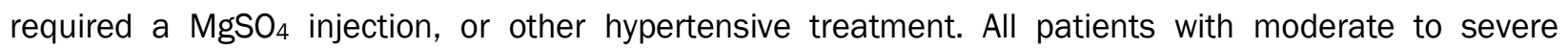
hypertension at intervention facilities were provided alpha methyldopa; only 28 percent of intervention site providers received or detected moderate to severe hypertensive patients.

No maternal deaths occurred in any study PHC facility, however, a greater number of infants died in comparison referral facilities than in intervention referral facilities. Although maternal and perinatal outcomes were better among women managed at intervention PHC facilities, the sample sizes at both 
intervention and comparison PHC facilities (89 and 63 women, respectively) were too small for definite conclusions-yet the impacts of this intervention on PHC providers shows potential and could be useful in other parts of the country, as demonstrated in other countries (DeCorby et al 2018, Okoli et al 2015).

Pregnant women's lack of adherence to referral processes and late ANC attendance are major challenges revealed by this study. Qualitative findings from survivor interviews suggest that many women do not seek early ANC unless they experience problems, and some women did not experience prodromal signs or symptoms, which raises concerns about how women and families can detect early onset hypertension. This is an issue that needs further exploration (Carter et al 2017). Similarly, many women do not visit referral facilities if they believe they feel better, due to medication from PHC providers or rest, or instead believe that referral facility providers are likely unavailable.

Poor communication skills, from providers to their patients, and inadequate information provided to clients and their families about the severity of patient conditions or test results, very likely also play a role in patients' non-adherence to the referral process. Only two fifths of patients observed during CPIs were cautioned that severe headache and blurred vision should be considered serious problems requiring urgent medical attention. If women and their families do not understand the seriousness of their problems and their potential consequences, they may be less likely to seek care with urgency.

This study includes a few limitations, including non-independence of the samples. Paired sample analysis was impossible because of frequent PHC provider transfers between facilities, and new postings. DMOs did, however, mentor or train newly posted PHC providers, to ensure their competency for service.

This study was encompassed by a larger Ending Eclampsia study that trained providers on $\mathrm{MgSO}_{4}$ and $\mathrm{PE} / \mathrm{E}$, which may have affected provider knowledge and practices. The objectives of both studies are similar, but only this study prescribed anti-hypertensive drugs. Researchers also observed CPIs to assess quality of care, which introduced the potential of a Hawthorne effect.

To make these study findings robust, different data sources have been utilized, and findings have been compared. Nevertheless, this study demonstrates interesting results for policy-makers to consider for task shifting for anti-hypertensive drug prescription at PHC facilities, to improve maternal and perinatal outcomes. 


\section{Conclusions and Recommendations}

PHC providers (FWVs, SACMOs, nurses) should be allowed to prescribe anti-hypertensive drugs and refer patients to higher level facilities when needed. PHC providers are capable of correctly measuring BP, classifying it, prescribing single doses of alpha methyldopa, and referring patients other facilities for further management, in a timely manner. Because the health care system lacks the capacity to completely regulate PHC providers, they prescribe anti-hypertensive drugs for women with HDP, even though they are not permitted to do so-and mostly prescribe drugs that are contraindicated. This situation demands that PHC providers are provided with appropriate and accurate anti-hypertensive drug knowledge, and equipped with requisite skills, for safe provision of correct anti-hypertensive drugs and referrals for patients in appropriate time.

PHC providers should be trained for three days-on hypertension, $\mathrm{PE} / \mathrm{E}, \mathrm{MgSO}_{4}$ and antihypertensive drugs-as well as participating in a one day refresher workshop, after three months.

Many women are not completing their courses of referral. Further research of these women is recommended, to identify why they do not complete the referral process, what are the barriers to their completion of the referral process are, and ways to support their completion of the process.

To build upon the findings of this study, which examined the efficacy of a single dose of alpha methyldopa and referral, a life course study of the pregnancy period with anti-hypertensive drugs provided by PHC providers is recommended to assess PHC providers' abilities in identifying drug non-responsiveness, emerging danger signs and symptoms, appropriate times for hospitalization or physician intervention, in addition to assessing whether task sharing is correct and adequate.

Task sharing efforts, including anti-hypertensive drugs, particularly alpha methyldopa, that were part of this PHC PE/E implementation, are recommended for other parts of the country, to reduce maternal and perinatal morbidities and mortalities, and achieve Bangladesh's SDGs by 2030. 


\section{References}

1. Abalos E, C Cuesta, AL Grosso, D Chou, L Say. 2013. Global and regional estimates of preeclampsia and eclampsia: a systematic review. Eur J Obstet Gynecol Reprod Biol 170: 1-7.

2. Abalos E, Duley L, Steyn DW. 2007. Anti-hypertensive drug therapy for mild to moderate hypertension during pregnancy. Cochrane Database of Systematic Reviews 1: CD002252.*

3. Action on Pre-eclampsia. 2004. Pre-Eclampsia Community Guideline.

4. Mammaro A, S Carrara, A Cavaliere, S Ermito, A Dinatale, EM Pappalardo, M Militello, R Pedata. 2009. Hypertensive Disorders in Pregnancy. J Prenat Med 3(1): 1-5.

5. Mammaro A, S Carrara, A Cavaliere, S Ermito, A Dinatale, EM Pappalardo, M Militello, R Pedata. 2009. Hypertensive Disorders in Pregnancy. J Prenatal Med 3(1): 1-51.

6. Arulkumaran N and L Lightstone. 2013. Severe preeclampsia and hypertensive crises. Best Pract Res Clin Obstet Gynaecol 27: 877-884.

7. Brewer A, E Tsigas, L Poye, H Gamill. 2015. The preeclampsia registry: depth of information obtained from open-ended queries in an on-line patient questionnaire. Pregn Hypertens 5(1): 124.

8. Brown MA, MD Lindheimer, M de Swiet, AV Assche, JM Moutquin. 2001. The classification and diagnosis of the hypertensive disorders of pregnancy: statement from the international society for the study of hypertension in pregnancy (ISSHP). Hypertens Pregn 20(1): ix-xiv.

9. DeCorby-Watson K, G Mensah, K Bergeron, S Abdi, B Rempel, H Manson. 2018. Effectiveness of capacity building interventions relevant to public health practice: a systematic review. BMC Pub Health 18(1): 684.

10. DeCorby-Watson K, G Mensah, K Bergeron, S Abdi, B Rempel, H Manson. 2018. Effectiveness of capacity building interventions relevant to public health practice: a systematic review. BMC Pub Health 18(1): 684.

11. Duley L. 2009. The global impact of pre-eclampsia and eclampsia. Seminars in Perinatology 33(3): 130-137.

12. Gebbie KM and BJ Turnock. 2006. The public health workforce, 2006: New challenges. Health Affairs 25(4): 923-933. doi: 10.1377/hlthaff.25.4.923.

13. Hodgins S, J Tielsch, K Rankin, A Robinson, A Kearns, J Caglia. 2016. A New Look at Care in Pregnancy: Simple, Effective Interventions for Neglected Populations. PLoS ONE 11(8): e0160562. doi: 10.1371/journal.pone.0160562

14. Kanyangarara M, MK Munos, N Walker. 2017. Quality of antenatal care service provision in health facilities across sub-Saharan Africa: Evidence from nationally representative health facility assessments. J Glob Health 7.

15. Khan KS, D Wojdyla, L Say, AM Gülmezoglu, PF Van Look. 2006. WHO analysis of causes of maternal death: a systematic review. Lancet 367(9516): 1066-1074.

16. Meads CA, JS Cnossen, S Meher et al. 2008. Methods of prediction and prevention of pre-eclampsia: systematic reviews of accuracy and effectiveness literature with economic modelling. Health Tech Assess 12(6): 40. 
17. Ansari N, P Manalai, F Maruf, S Currie, J Stekelenburg, J van Roosmalen, YM Kim, H Tappis. 2019. Quality of care in early detection and management of pre-eclampsia/eclampsia in health facilities in Afghanistan. BMC Preg Childbirth 19: 36.

18. National Collaborating Centre for Women's and Children's Health et al. 2011. Hypertension in pregnancy: the management of hypertensive disorders during pregnancy. 2011. National Collaborating Centre for Women's and Children's Health, Royal College of Obstetricians and Gynaecologists, Royal College of Paediatrics and Child Health, Royal College of Midwives: London.

19. National Institute for Health and Clinical Excellence (NICE). 2011. Hypertension in pregnancy: The management of hypertensive disorders during pregnancy. UK: NICE.

20. National Institute of Population Research and Training (NIPORT), International Centre for Diarrhoeal Disease Research, Bangladesh (icddr,b), MEASURE Evaluation. 2017. Bangladesh Maternal Mortality and Health Care Survey 2016: Preliminary Report. Dhaka and Chapel Hill, NC, USA: NIPORT, icddr,b, and MEASURE Evaluation.

21. Okoli U, E Eze-Ajoku, M Oludipe, N Speiker, W Ekezie, K Ohiri. 2016. Improving Quality of Care in Primary Health-Care Facilities in Rural Nigeria: Successes and Challenges. Health Serv Res Manag Epidemiol.

22. Oladapo OT, OO Adetoro, BA Ekele, C Chama, SJ Etuk et al. 2015. Nigeria Near-miss and Maternal Death Surveillance Network. When getting there is not enough: a nationwide cross-sectional study of 998 maternal deaths and 1451 near-misses in public tertiary hospitals in a low-income country. BJOG. doi: 10.1111/1471-0528.13450.

23. Preeclampsia Foundation. 2016. Preeclampsia and Maternal Mortality: A Global Burden. www.preeclampsia.org/health-information/149-advocacy-awareness/332-preeclampsia-andmaternal-mortality-a-global-burden

24. Reference of service delivery protocol

25. Say L, D Chou, A Gemmill, Ö Tunçalp, AB Moller, J Daniels, AM Gülmezoglu, M Temmerman, L Alkema. 2014. Global causes of maternal death: a WHO systematic analysis. Lancet Glob Health 2(6): e323e333. doi: 10.1016/S2214-109X(14)70227-X.

26. Sibai BM. 2005. Diagnosis, prevention, and management of eclampsia. Obstet Gynecol 105(2): 402410.

27. Steegers EA, P von Dadelszen, JJ Duvekot, R Pijnenborg. 2010. Pre-eclampsia. Lancet 376(9741): 631-644.

28. Hodgins S, J Tielsch, K Rankin, A Robinson, A Kearns, J Caglia. 2018. A New Look at Care in Pregnancy: Simple, Effective Interventions for Neglected Populations. PLOS ONE. doi:10.1371/journal.pone.0160562

29. Warren C, S Hossain, RA Nur, K Sultana, KR Kirk, A Dempsey. 2016. Landscaping analysis on preeclampsia and eclampsia in Bangladesh. Dhaka: Population Council.

30. Carter W, D Bick, N Mackintosh, J Sandall. 2017. A narrative synthesis of factors that affect women speaking up about early warning signs and symptoms of pre-eclampsia and responses of healthcare staff. BMC Preg Childbirth 17: 63

31. World Health Organization 2008. Task shifting: rational redistribution of tasks among health workforce teams: global recommendations and guidelines. Geneva: WHO. 
32. World Health Organization 2012. Optimizing health worker roles to improve access to key maternal and newborn health interventions through task shifting.

33. World Health Organization. 2005. Make Every Mother and Child Count. The World Health Report 2005. Geneva: World Health Organization.

34. World Health Organization. 2007. Maternal mortality in 2005: estimates developed by WHO, UNICEF, UNFPA and the World Bank. Geneva: World Health Organization.

35. World Health Organization. 2011. WHO recommendations for prevention and treatment of preeclampsia and eclampsia. Geneva: WHO. 


\section{Appendix A}

Flow chart for diagnosis and management of HDPs
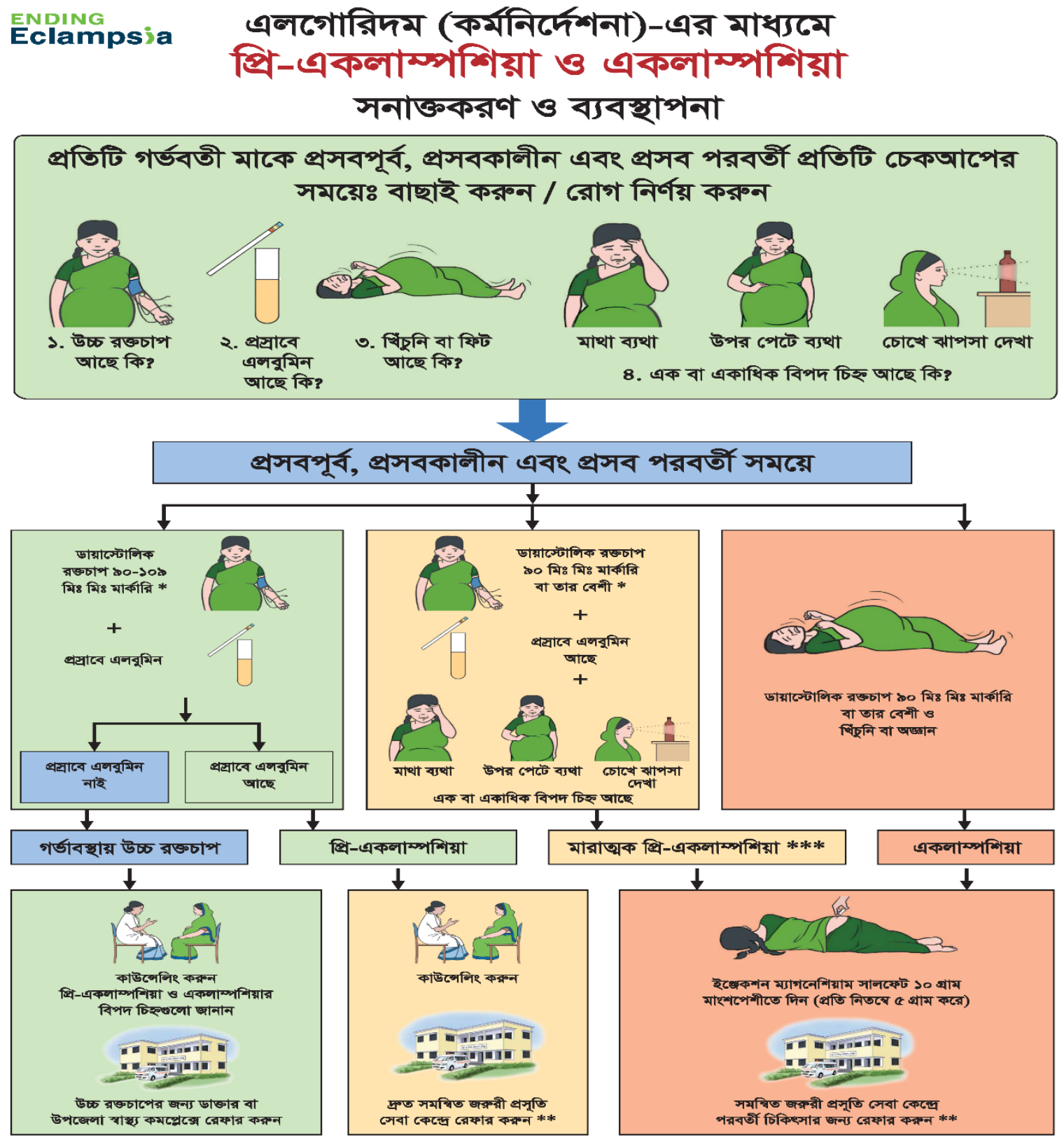

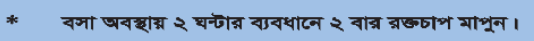

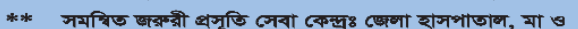

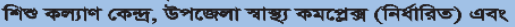
ब্ভিকেন কढেख হাসপাতानসयूर।

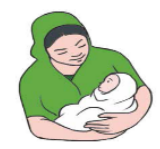

मूস्र

मा ৫

गिए

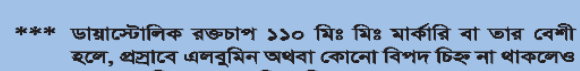

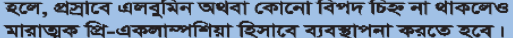




\section{Appendix B}

Decision making tree for diagnosis, management, action and referral for PE/E

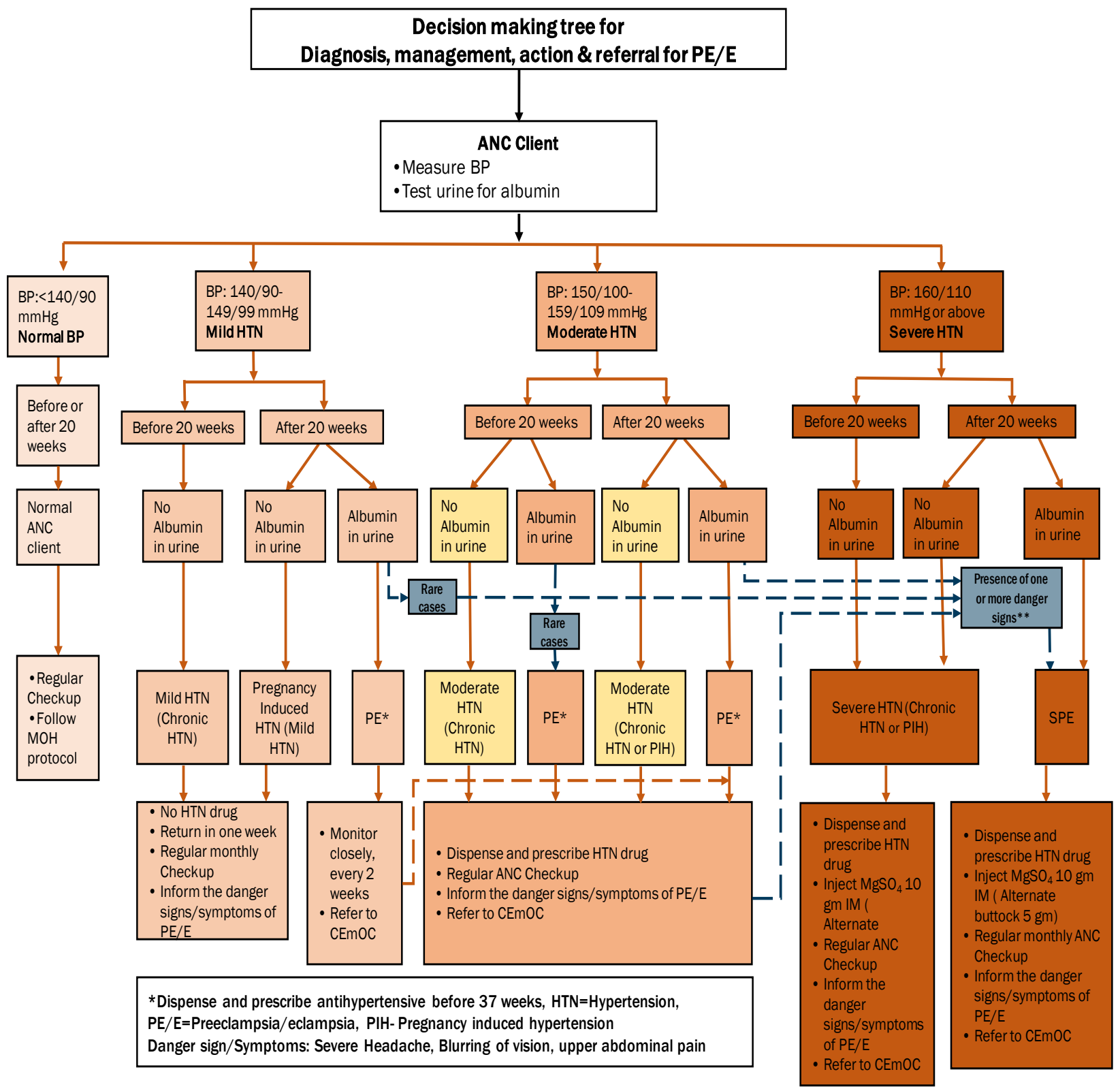




\section{Appendix C}

Referral pathways

\section{রেফারেলের যোগসুত্র (Referral Linkage)}

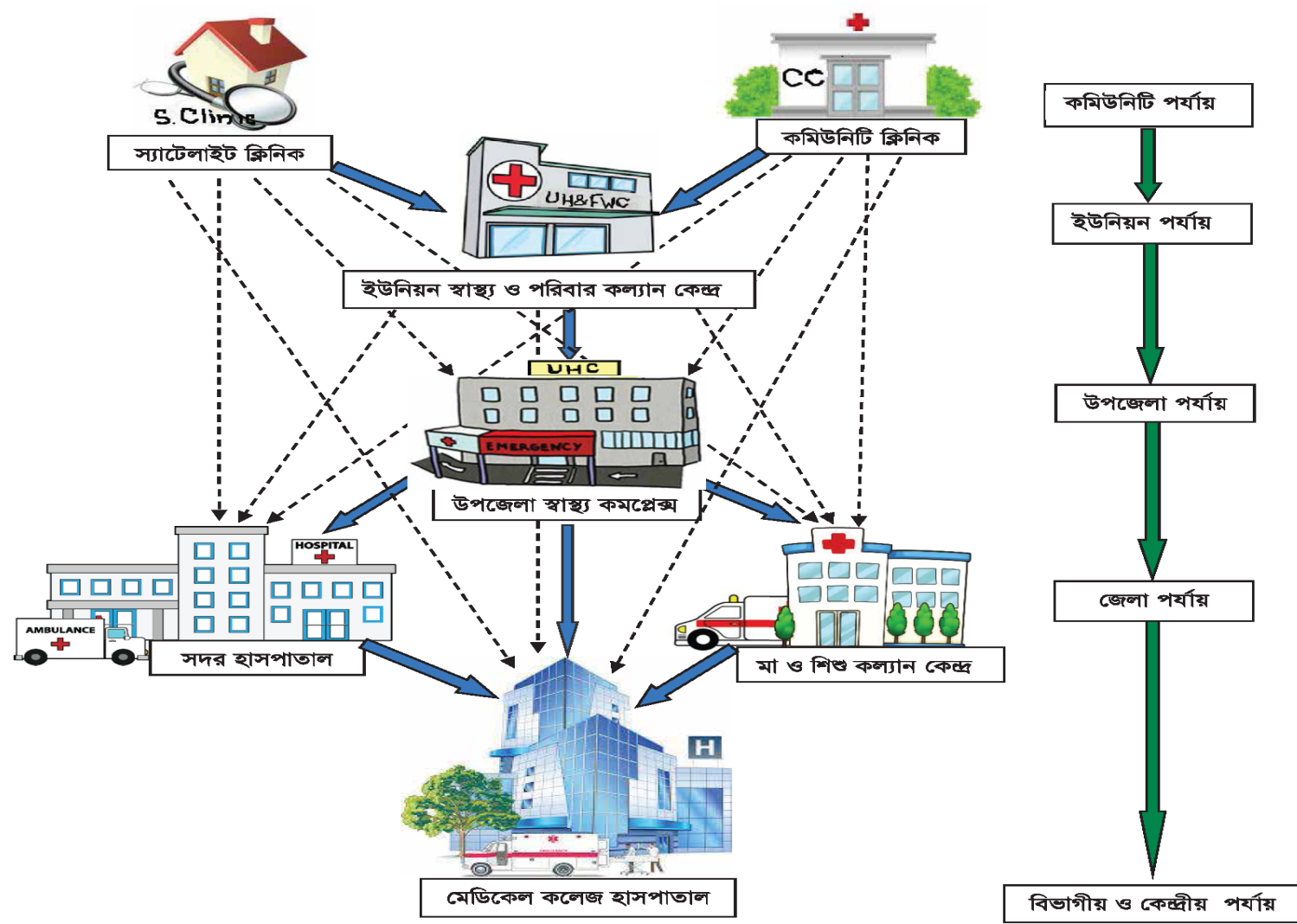

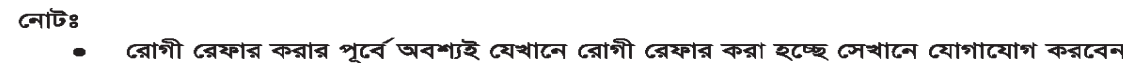

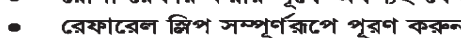

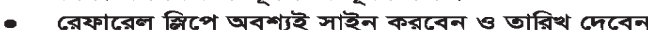

- রেফারেল ন্লিপের ভ্রকটি কপি রোগীর সাথে দিন এবং অন্য কপিটি নথি হিসাবে সংরক্ষণ করুন

- একলাম্পশিয়া র্যোগী রেফার করের সময় অবশ্যই একজন দক্ষ সেবা কর্মী রেফার্নেল কেন্দ পর্যন্ত সাথে যাবেন

(3) UAID
POPULATION

COUNCIL

Ideas. EMdence. Impact. (c⿻)

\section{Appendix D}


Service utilization
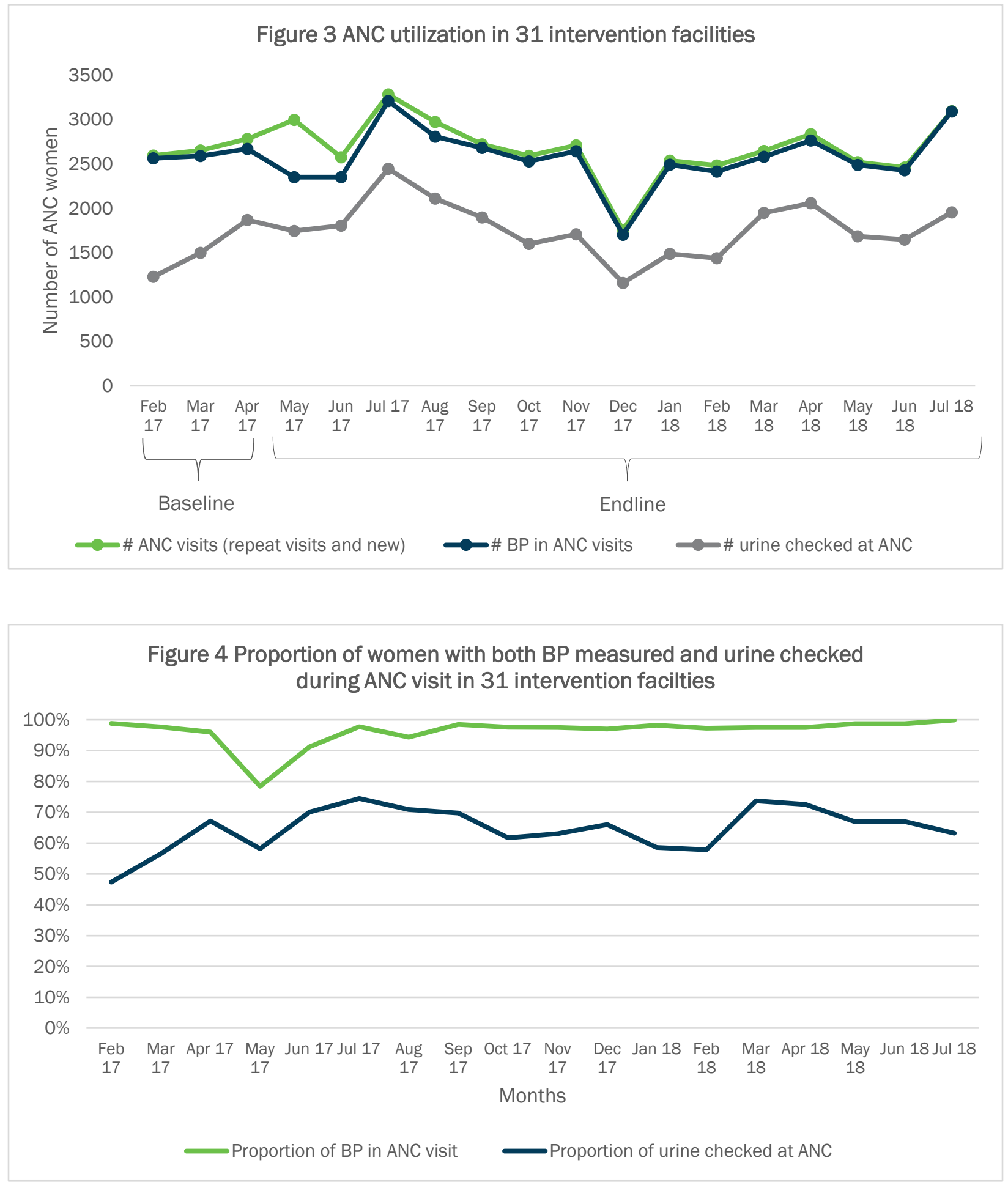
Figure 5 ANC utilization in 23 comparison facilities

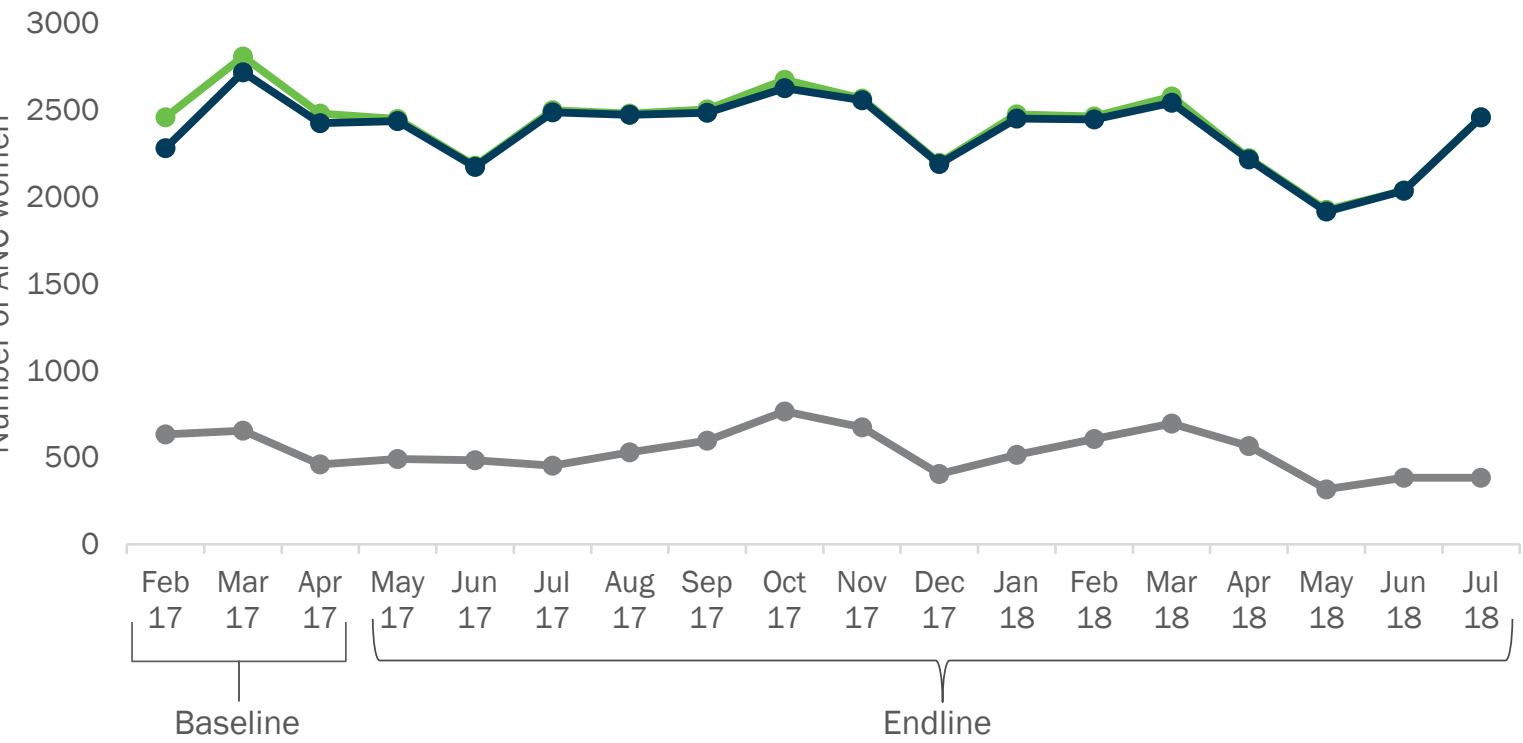

\# ANC visits (repeat visits and new) $\quad \longrightarrow$ \# B Brine checked at ANC

Figure 6 Proportion of women with BP measured and urine checked during ANC visit in 23 comparison facilities

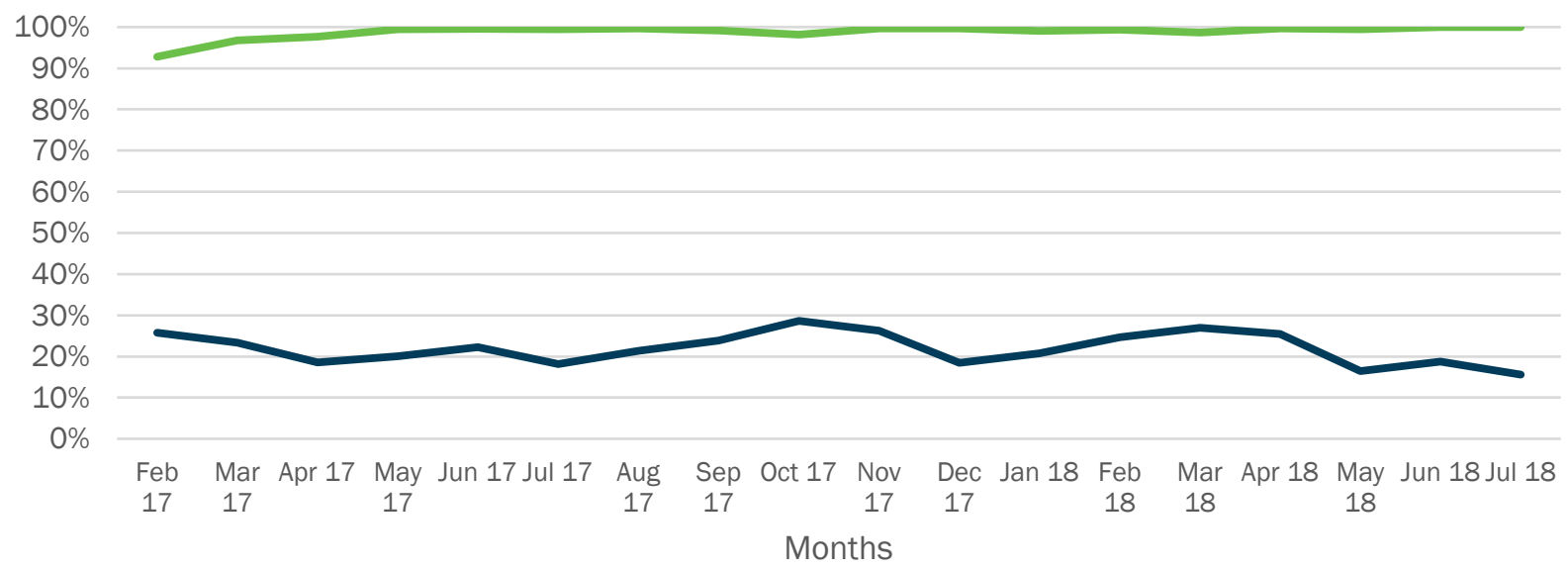

Proportion of BP in ANC visit $\quad$ Proportion of urine checked at ANC 


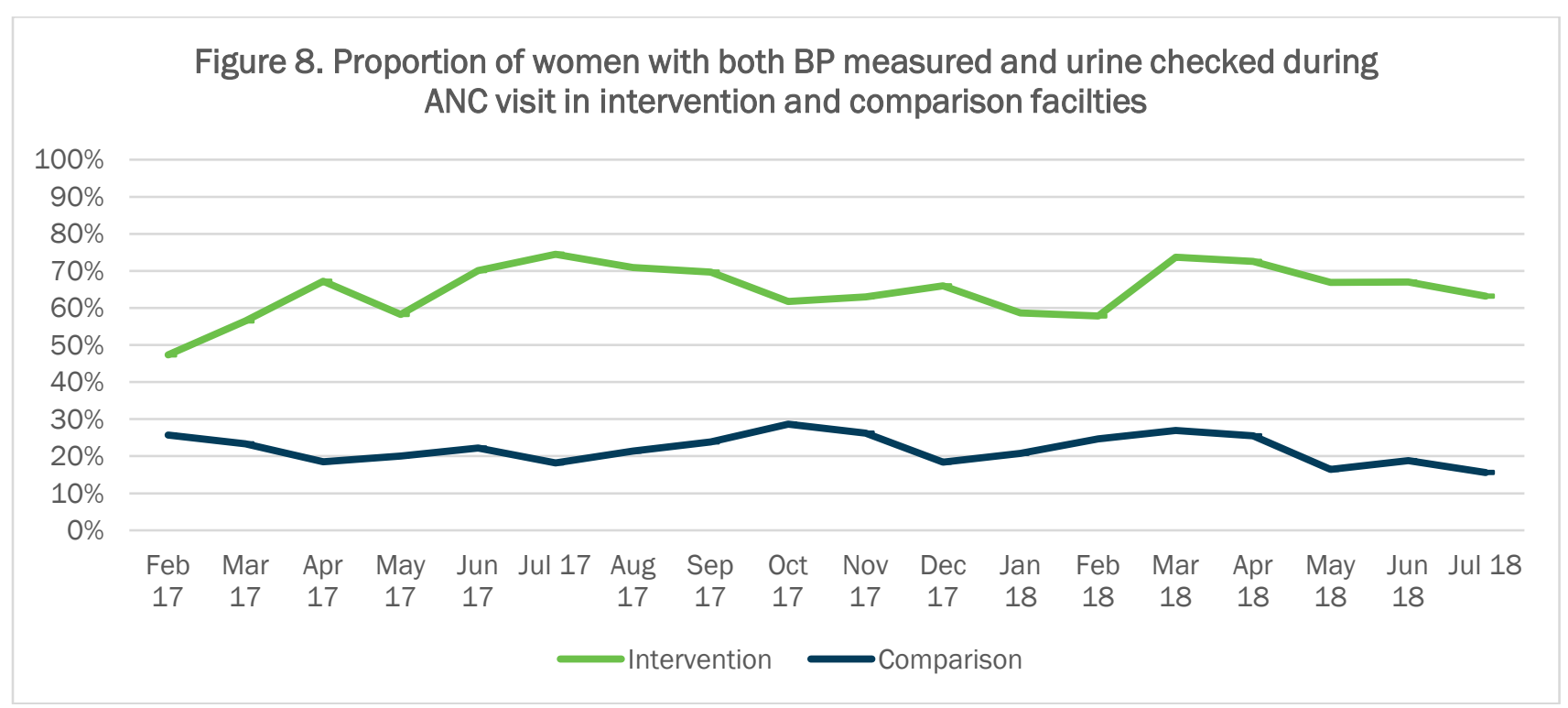

Figure 9 Monthly detection of moderate to severe hypertension in ANC visits at intervention and comparison facilities during intervention period

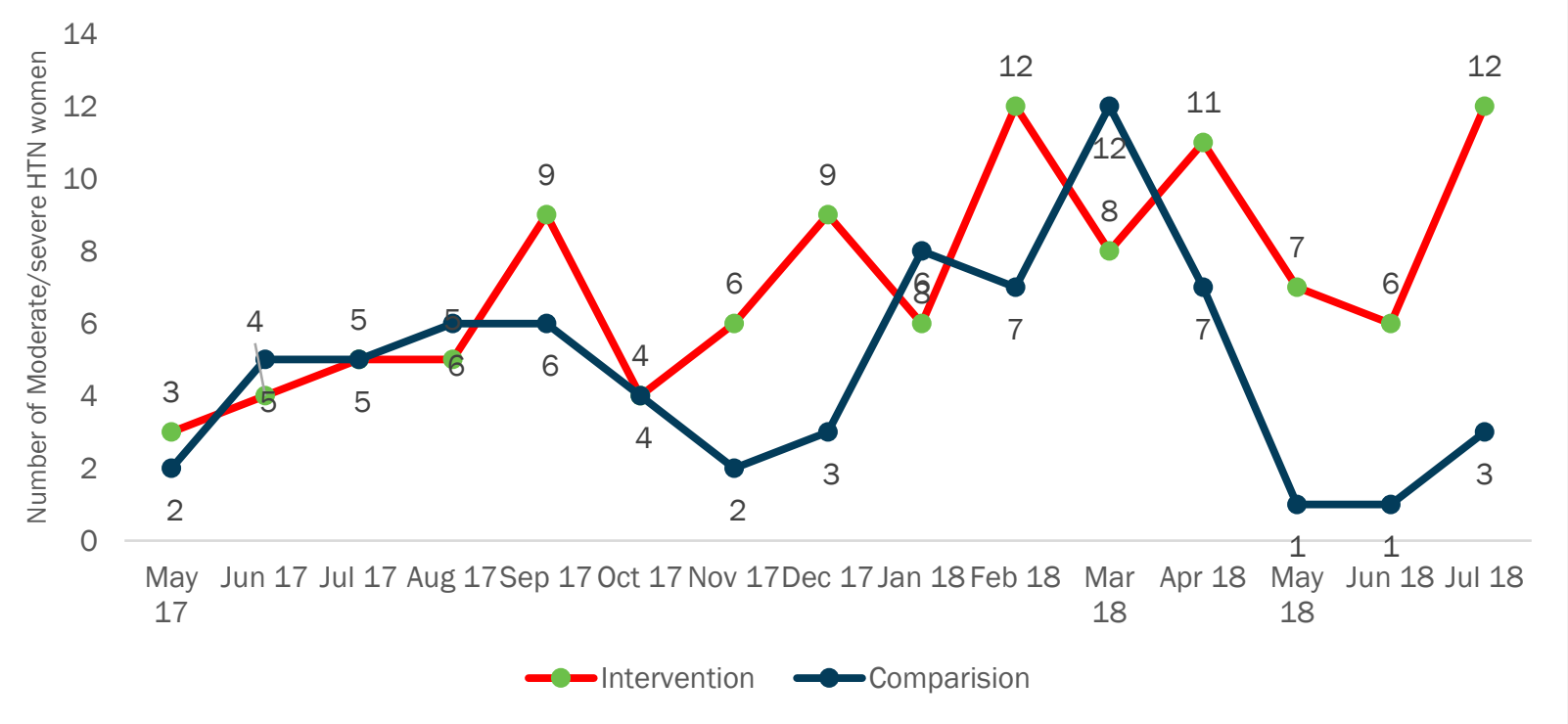

